\title{
Experimental and Computational Study of the Magnetic Properties of $\mathrm{ZrMn}_{2-\mathrm{x}} \mathrm{Co}_{\mathrm{x}} \mathrm{Ge}_{4} \mathrm{O}_{12}$
}

\section{Diming $\mathrm{Xu}^{1}$, Matthew Sale ${ }^{2,3}$, Maxim Avdeev ${ }^{2,3}$, Chris D. Ling $^{2,3}$ and Peter D. Battle ${ }^{1, *}$}

1. Inorganic Chemistry Laboratory, Oxford University, South Parks Road, Oxford, OX1 3QR, U. K.

2. Australian Nuclear Science and Technology Organisation, Lucas Heights, NSW 2234, Australia

3. School of Chemistry, The University of Sydney, Sydney, NSW 2006, Australia

* to whom correspondence should be addressed: peter.battle@chem.ox.ac.uk 


\begin{abstract}
Polycrystalline samples in the solid solution $\mathrm{ZrMn}_{2-\mathrm{x}} \mathrm{Co}_{\mathrm{x}} \mathrm{Ge}_{4} \mathrm{O}_{12}(x=0.0,0.5,1.0,1.5$ and 2.0) have been prepared using the ceramic method and characterised by a combination of magnetometry, X-ray diffraction and neutron diffraction. They all adopt the space group $P 4 / n b m$ with $a \sim 9.60, c \sim 4.82 \AA$ and show long-range magnetic order with transition temperatures, $T_{\mathrm{C}}$, in the range $2 \leq T_{\mathrm{C}} / \mathrm{K} \leq 10$. The underlying magnetic structure is the same in each case but the ordered spins lie along [001] when $x=0.0$ and in the (001) plane for all other compositions. In all cases the magnetically-ordered phase is a weak ferromagnet although the magnitude of the spontaneous magnetisation and the strength of the coercive field are composition-dependent. The magnetic structure can be rationalized by considering the strengths of the interactions along the distinct $M-\mathrm{O}-\mathrm{Ge}-\mathrm{O}-M$ superexchange pathways in the crystal and the observed magnetic structure is entirely consistent with the predictions of $a b$ initio calculations.
\end{abstract}




\section{Introduction}

When cooled below a critical temperature, many simple transition-metal oxides and halides undergo a transition to an antiferromagnetic (AFM) state. However, compounds that are isostructural in the paramagnetic phase can adopt different low-temperature magnetic structures, for example $\mathrm{MnO}$ and $\mathrm{CoO}^{1}$. Although both of these can be described as Type II antiferromagnets ${ }^{2}$, the atomic moments align along different crystallographic axes within the unit cell. Furthermore, the nature of the non-cubic strain is not the same in the two magnetic phases. As in many comparable cases ${ }^{3}$, this can be attributed to the fact that six-coordinate $\mathrm{Co}^{2+}: 3 d^{7}$ has a large single-ion anisotropy associated with it, whereas the spherical $\mathrm{Mn}^{2+}: 3 d^{5}$ cation does not. Studies of solid solutions have often been used to elucidate the relative strength of the anisotropy associated with the two different cations 4.

This composition-dependent variation in magnetic behaviour is not restricted to simple binary oxides and halides and we have recently shown ${ }^{5}$ that $\mathrm{CeMn}_{2} \mathrm{Ge}_{4} \mathrm{O}_{12}$ and $\mathrm{CeCo}_{2} \mathrm{Ge}_{4} \mathrm{O}_{12}$ behave very differently at low temperatures. They both crystallise in the space group $P 4 / \mathrm{nbm}$ with the $2 b$ site being occupied by cerium and the $4 f$ site by cobalt or manganese. These two cation sites are coordinated by eight and six oxygen atoms, respectively, and have squareantiprismatic and octahedral geometries. They can be considered to lie in layers perpendicular to the [001] axis. These layers are separated from each other by layers containing $\left[\mathrm{Ge}_{4} \mathrm{O}_{12}\right]^{8-}$ rings, each ring being comprised of four vertex-sharing $\mathrm{GeO}_{4}$ tetrahedra, see Figure 1. $\mathrm{CeMn}_{2} \mathrm{Ge}_{4} \mathrm{O}_{12}$ was found to be magnetically ordered below $7.6 \mathrm{~K}$. Although magnetometry measurements made in fields of less than 100 Oe suggested that the ordering involves a very weak ferromagnetic (FM) component, neutron powder diffraction (NPD) indicated that the atomic moments on nearest-neighbour cations align antiparallel along [001]. The replacement of $\mathrm{Mn}^{2+}$ by $\mathrm{Co}^{2+}$ to form the solid solution $\mathrm{CeMn}_{2-\mathrm{x}} \mathrm{Co}_{\mathrm{x}} \mathrm{Ge}_{4} \mathrm{O}_{12}$ caused the spins to move into the (001) plane although the same magnetic structure was initially retained. However, for $x \geq 1.5$ the magnetic unit cell doubled in size along [001] and the spin structure consisted of an antiferromagnetic stacking of weakly ferromagnetic sheets. The application of a magnetic field of $10 \mathrm{kOe}$ induced a metamagnetic transition that eliminated the doubling of the unit cell volume and resulted in the adoption of a weakly ferromagnetic structure.

In this paper we report a study in which we have used magnetometry and in-field NPD to monitor the changes in magnetic structure that occur as a function of composition in the solid solution $\mathrm{ZrMn}_{2-\mathrm{x}} \mathrm{Co}_{\mathrm{x}} \mathrm{Ge}_{4} \mathrm{O}_{12}$. We contrast this system with the cerium-containing phases 
described above in order to identify the aspects of the magnetic behaviour that are sensitive to the size or electronic structure of the diamagnetic, tetravalent cation in these isostructural compounds. In the case of the $\mathrm{ZrMn}_{2-\mathrm{x}} \mathrm{Co}_{\mathrm{x}} \mathrm{Ge}_{4} \mathrm{O}_{12}$ system we have also performed $a b$ initio (density functional theory, DFT) calculations in order to quantify the relative strengths of the different superexchange interactions that operate in this structure.

\section{Experimental}

Polycrystalline samples of $\mathrm{ZrMn}_{2-\mathrm{x}} \mathrm{Co}_{\mathrm{x}} \mathrm{Ge}_{4} \mathrm{O}_{12}$ were synthesized using a solid-state method for compositions in the range $0 \leq \mathrm{x} \leq 2$. Initially, stoichiometric quantities of $\mathrm{ZrO}_{2}$ (99.978\%), $\mathrm{Co}_{3} \mathrm{O}_{4}(99.9985 \%), \mathrm{MnCO}_{3}(99.985 \%)$ and $\mathrm{GeO}_{2}(99.9999 \%)$ were ground together and the resulting mixtures were heated at $1075{ }^{\circ} \mathrm{C}$ for one day. They were then pressed into a pellet and annealed at $1125^{\circ} \mathrm{C}$ for a total of 16 days with intermediate cooling and regrinding every two days. The course of the reactions was monitored by X-ray powder diffraction (XRPD). After a number of trials the composition of the reaction mixture was modified to include a small excess of $\mathrm{GeO}_{2}$ and a slightly sub-stoichiometric quantity of $\mathrm{ZrO}_{2}$. This protocol countered the volatility of $\mathrm{GeO}_{2}$ and minimised the formation of impurity phases, most notably $\mathrm{CoGeO}_{3}$. XRPD data were collected on the final reaction products at room temperature using a Panalytical X'pert diffractometer operating with monochromated $\mathrm{Cu} \mathrm{K} \alpha_{1}$ radiation. Data were collected in the range $10 \leq 2 \theta /^{\circ} \leq 130$ with a step size $\Delta 2 \theta=0.0084^{\circ}$ and analysed by the Rietveld method ${ }^{6}$ as implemented in the GSAS program suite ${ }^{7}$. The magnetic properties of all the reaction products were measured with a Quantum Design MPMS 5000 SQUID magnetometer. In each case the dc magnetic susceptibility was measured over the temperature range $2 \leq T / K \leq 300$ after both zero-field-cooling (ZFC) and field-cooling (FC) in an applied field of 100 Oe. Additional measurements in other fields were made in the case of $\mathrm{ZrMn}_{2} \mathrm{Ge}_{4} \mathrm{O}_{12}$, see below. For each sample, the field dependence of the magnetization was measured over the field range $-30 \leq \mathrm{H} / \mathrm{kOe} \leq 30$ at $2 \mathrm{~K}$. The ac susceptibilities were measured at frequencies up to $1 \mathrm{kHz}$ over the temperature range $2 \leq T / K \leq 10$ using a 3.5 Oe ac field. $\mathrm{ZrMn}_{2} \mathrm{Ge}_{4} \mathrm{O}_{12}, \mathrm{ZrMnCoGe}_{4} \mathrm{O}_{12}$ and $\mathrm{ZrCo}_{2} \mathrm{Ge}_{4} \mathrm{O}_{12}$ were selected for further study by NPD. Data were collected on the high-resolution powder diffractometer Echidna at ANSTO. The angular range of $8 \leq 2 \theta /^{\circ} \leq 160$ was scanned using a step size of $\Delta 2 \theta=0.05^{\circ}$ with a wavelength of $1.622 \AA$ or $2.4397 \AA$. Some patterns were collected with the sample mounted in a vertical-field cryomagnet. In these cases, in order to 
prevent movement in the magnetic field, the sample was pressed into a pellet which was subsequently broken into fragments, each just small enough to be loaded into a standard vanadium container. Regions of the diffraction profile that were contaminated by Bragg peaks from aluminium in the cryomagnet were excluded from the subsequent analysis. In other cases the sample was loaded in powder form and the vanadium can was mounted in a closed-cycle refrigerator. Rietveld analysis of the data was carried out using the peak shape function developed by van Laar and Yelon ${ }^{8}$.

\section{Computational Method}

$\mathrm{ZrMn}_{2} \mathrm{Ge}_{4} \mathrm{O}_{12}$ and $\mathrm{ZrCo}_{2} \mathrm{Ge}_{4} \mathrm{O}_{12}$ were modelled using density functional theory (DFT) as implemented in the Vienna Ab-initio Simulation Package (VASP, version 5.2.12) ${ }^{9-13}$ in the generalized gradient approximation (GGA) of Perdew, Burke and Ernzerhof ${ }^{14}$ with the projector augmented-wave (PAW) method ${ }^{13,15}$. A $\Gamma$-centered 5x5x5 Monkhorst-Pack k-point mesh ${ }^{16}$ with Gaussian smearing ${ }^{17}$ was used in the calculations with a plane wave energy cutoff of $600 \mathrm{eV}$; tests were performed to verify that this combination of mesh size and cut-off energy resulted in a converged system. The GGA plus onsite repulsion $(\mathrm{GGA}+U)$ method was used to correct the well-known over-binding of electrons in $3 d$ metal atoms ${ }^{18}$. A $1 \times 1 \times 2$ supercell was initially used in the relaxation of the structure and for the calculation of the spin exchange constants of these materials. Final calculations of magnetic energies using a larger unit cell of $\left(\mathbf{a}_{\mathrm{c}}=2 \mathbf{a}, \mathbf{b}_{\mathrm{c}}=\mathbf{b}, \mathbf{c}_{\mathrm{c}}=\mathbf{a}+2 \mathbf{c}\right)$ utilised a $2 \times 4 \times 4$ k-point mesh and an energy cutoff of $500 \mathrm{eV}$. The use of this cell allowed us to consider magnetic structures other than that found by experiment and to determine the relevant spin exchange constants, see below. Ionic relaxation was performed starting with the experimental crystal and magnetic structures and $U$-values of 5.0 and $4.0 \mathrm{eV}$ for $\mathrm{ZrMn}_{2} \mathrm{Ge}_{4} \mathrm{O}_{12}$ and $\mathrm{ZrCo}_{2} \mathrm{Ge}_{4} \mathrm{O}_{12}$, respectively. All unit cell parameters were allowed to vary and the relaxations were re-started several times to eliminate the effects of Pulay stress ${ }^{19}$. Even though no space-group symmetry was imposed on the degrees of freedom of the atomic positions, the final symmetry was the same as the original space-group symmetry. The atomic positions of these relaxed structures were subsequently used to calculate magnetic energies using an isotropic Heisenberg model. The exchange constants and the Weiss temperature, $\theta$, were subsequently derived from these energies, the latter using mean-field theory. Calculations performed to establish the sensitivity of the exchange constants to variations in $\mathrm{U}$ over the range $3<\mathrm{U} / \mathrm{eV}<6$ by matching the calculated and experimental Curie-Weiss temperatures led to the conclusion that the chosen values, $\mathrm{U}=$ 
5 and $4 \mathrm{eV}$, were appropriate values to use for $\mathrm{ZrMn}_{2} \mathrm{Ge}_{4} \mathrm{O}_{12}$ and $\mathrm{ZrCo}_{2} \mathrm{Ge}_{4} \mathrm{O}_{12}$. (Details of these calculations are available in the ESI that accompanies this paper.) These values are similar to those used on other magnetic oxide materials with the same magnetic cations ${ }^{20,21}$. The superexchange interactions that need to be taken into account within this structure were described in our earlier account of $\mathrm{CeMn}_{2-\mathrm{x}} \mathrm{Co}_{\mathrm{x}} \mathrm{Ge}_{4} \mathrm{O}_{12}$. For the purposes of our computational study, the corresponding exchange constants were labelled as follows: $\mathrm{J}_{1}$; the interaction between nearest-neighbour $(\mathrm{NN})$ cations along [001]; $\mathrm{J}_{2}$, the interaction between $\mathrm{NN}$ cations within a (001) plane; $\mathrm{J}_{3}$ and $\mathrm{J}_{4}$, two similar but unequal interactions along $\langle 101\rangle$ between cations in neighbouring planes; $\mathrm{J}_{5}$ and $\mathrm{J}_{6}$, two similar but unequal interactions between nextnearest-neighbour (NNN) cations in a (001) plane, see Figure 2. $\mathbf{J}_{3}$ and $\mathbf{J}_{4}$ differ in that the former pathway involves $\mathrm{O} 1$ and the latter involves $\mathrm{O} 2 ; \mathrm{J}_{5}$ and $\mathrm{J}_{6}$ in that the latter involves $\mathrm{Zr}$ whereas the former does not. Our initial calculations in a $1 \times 1 \times 2$ supercell were unable to distinguish the individual interaction strengths within the pairs $\mathrm{J}_{3}, \mathrm{~J}_{4}$. and $\mathrm{J}_{5}, \mathrm{~J}_{6}$; only mean values could be calculated. However, it became apparent that the interactions along <101> represented by $\mathrm{J}_{3}$ and $\mathrm{J}_{4}$ were amongst the strongest in the structure and further calculations in the enlarged supercell with $\mathbf{a}_{\mathrm{c}}=2 \mathbf{a}, \mathbf{b}_{\mathrm{c}}=\mathbf{b}, \mathbf{c}_{\mathrm{c}}=\mathbf{a}+2 \mathbf{c}$, see Figure 14, were therefore undertaken in order to separate their contributions. Given that our initial calculations showed that the $\mathrm{NNN}$ interactions represented by $\mathrm{J}_{5}$ and $\mathrm{J}_{6}$ were very weak, no further calculations were undertaken in order to resolve their individual contributions. The values of $U$ derived using the $1 \times 1 \times 2$ supercell were used in the calculations based on the enlarged supercell.

\section{Results}

Samples of $\mathrm{ZrMn}_{2-\mathrm{x}} \mathrm{Co}_{\mathrm{x}} \mathrm{Ge}_{4} \mathrm{O}_{12}$ were prepared for $\mathrm{x}=0,0.5,1.0,1.5$ and 2; the cobaltcontaining compositions were pink whereas $\mathrm{ZrMn}_{2} \mathrm{Ge}_{4} \mathrm{O}_{12}$ was brown. The principal phase apparent in the XRPD pattern of every sample could be indexed in the tetragonal space group $P 4 / n b m$; the refined unit cell parameters are listed in Table 1 . The intensity distribution in the XRPD, exemplified by that of $\mathrm{ZrCo}_{2} \mathrm{Ge}_{4} \mathrm{O}_{12}$ in Figure 3, was consistent with the crystal structure previously assigned to $\mathrm{Y}_{2} \mathrm{CaGe}_{4} \mathrm{O}_{12}{ }^{22}$ with the $2 b$ site now occupied by $\mathrm{Zr}^{4+}$ and the $4 f$ site by a disordered distribution of divalent transition-metal cations. The XRPD patterns collected from samples of $\mathrm{ZrCo}_{2} \mathrm{Ge}_{4} \mathrm{O}_{12}$ and $\mathrm{ZrMn}_{0.5} \mathrm{Co}_{1.5} \mathrm{Ge}_{4} \mathrm{O}_{12}$ contained weak Bragg peaks, see Figure 3, from a $\mathrm{CoGeO}_{3}$ impurity phase. Quantitative analysis of the patterns suggested impurity levels of 5(1) and 1.3(6) wt. \%, respectively. 
The temperature dependence of the molar dc magnetic susceptibility and the field dependence of the magnetisation of each sample are shown in Figure 4. Every composition undergoes a magnetic transition below $10 \mathrm{~K}$. The molar Curie constant, $\mathrm{C}_{\mathrm{m}}$, and the Weiss constant, $\theta$, derived by fitting the magnetic susceptibility to the Curie-Weiss Law in the temperature range $150 \leq \mathrm{T} / \mathrm{K} \leq 300$ are listed in Table 2 . Hysteresis is apparent in $\mathrm{M}(\mathrm{H})$ for all the cobaltcontaining samples; the coercive field, $\mathrm{H}_{\mathrm{C}}$, and the remanent magnetisation, $\mathrm{M}_{\mathrm{R}}$, are also listed in Table 2. No hysteresis was detected in $\mathrm{M}(\mathrm{H})$ for $\mathrm{ZrMn}_{2} \mathrm{Ge}_{4} \mathrm{O}_{12}$, although the function was nonlinear. The temperature dependence of the ac susceptibilities of all five compositions is shown in Figure 5. Again, a transition is always observed below $10 \mathrm{~K}$. The transition temperature, $T_{C}$, is not frequency dependent but below $T_{C}$ the susceptibility is frequency dependent and complex, suggesting that the sample has developed a spontaneous magnetisation. An accurate value of $\mathrm{T}_{\mathrm{C}}$ for each composition is included in Table 2. In view of the apparent absence of hysteresis in $\mathrm{M}(\mathrm{H})$ for $\mathrm{ZrMn}_{2} \mathrm{Ge}_{4} \mathrm{O}_{12}$, despite the presence of an imaginary component in the ac susceptibility, further dc measurements were made in applied fields of $0.01 \leq \mathrm{H} / \mathrm{kOe} \leq 10$, see Figure 6 . Hysteresis indicative of a spontaneous magnetisation can be seen below the transition temperature in the data recorded in 10 Oe but not in those measured in $1000 \mathrm{Oe}$. The small, secondary maximum seen at $6 \mathrm{~K}$ in the ac susceptibility is matched by a break in the ZFC dc susceptibility measured in 10 Oe, see Figure 6(b).

Neutron diffraction data were collected at temperatures selected in the light of the susceptibility data described above. In the case of $\mathrm{ZrMn}_{2} \mathrm{Ge}_{4} \mathrm{O}_{12}$, data were collected at room temperature and $3.5 \mathrm{~K}$ using a wavelength of $1.622 \AA$. The pattern collected at $3.5 \mathrm{~K}$, but not that collected at room temperature, contained Bragg scattering at low angles that could not be accounted for using the structural model used to analyse the XRPD data and this additional scattering was therefore assumed to be magnetic in origin. Figure 7 shows the Rietveld fit achieved using a structural model based on $\mathrm{Y}_{2} \mathrm{CoGe}_{4} \mathrm{O}_{12}{ }^{23}$ and the antiferromagnetic structure drawn in Figure $8{ }^{24}$; the magnetic unit cell and the structural unit cell are the same size. The ordered moment of each $\mathrm{Mn}^{2+}$ cation is aligned along $\pm \mathrm{z}$. The coupling between it and the moments of the four nearest-neighbour $\mathrm{Mn}^{2+}$ cations lying in the same $x y$ plane at $z=$ 0.5 is antiferromagnetic whereas the coupling to the four next-nearest neighbour cations in this plane is ferromagnetic. The nearest-neighbour coupling along [001] is ferromagnetic and the magnetic structure can thus be described as a ferromagnetic stacking of antiferromagnetic sheets. Given the relationship $c \sim a / 2$ between the unit cell parameters, the arrangement of the transition-metal cations in this structure can be described as pseudo-cubic and the magnetic 
structure drawn in Figure 8 can thus be described as C-type ${ }^{25}$. Formally, the magnetic structure in Figure 8 can be described by the magnetic space group P4'/nbm' (\#125.5.1035), although the true magnetic symmetry is likely to be lower as this magnetic space group does not allow the ferromagnetic component that was observed by magnetometry. The structural parameters derived from the data collected at room temperature and $3.5 \mathrm{~K}$ are listed in Table 3 and selected bond lengths and bond angles are presented in Table 4. Data were subsequently collected using a wavelength of $2.4397 \AA$ at $15 \mathrm{~K}$; no magnetic Bragg scattering was apparent in this diffraction pattern, see Figure 9. Finally, three data sets were collected successively at $1.6 \mathrm{~K}$ in magnetic fields of 0,30 and $0 \mathrm{kOe}$. No changes in either the crystal structure or the magnetic structure were detected when the field was applied; the ordered moments derived from the three analyses were 4.68(2) and 4.23(2) and 4.66(2) $\mu_{\mathrm{B}}$ per $\mathrm{Mn}^{2+}$, respectively.

The structural parameters and bond lengths determined for $\mathrm{ZrCo}_{2} \mathrm{Ge}_{4} \mathrm{O}_{12}$ at room temperature using a wavelength of $1.622 \AA$ are listed in Tables 3 and 4, respectively. Paramagnetic $\mathrm{CoGeO}_{3}$ was included as a second phase in this analysis but the principal phase was assumed to have the ideal composition. This strategy is justified by the level of agreement between the observed and calculated diffraction patterns. The neutron diffraction pattern of $\mathrm{ZrCo}_{2} \mathrm{Ge}_{4} \mathrm{O}_{12}$ recorded at $1.6 \mathrm{~K}$ using a wavelength of $1.622 \AA$ contained Bragg scattering that could not be attributed to the crystal structure alone. However, it could be accounted for, see Figure 10, when the magnetic structure shown in Figure 11 and an antiferromagnetically ordered $\mathrm{CoGeO}_{3}$ impurity were included in the analysis. Again, the magnetic unit cell is the same size as the structural unit cell but the spin-ordering pattern is very different to that found in $\mathrm{ZrMn}_{2} \mathrm{Ge}_{4} \mathrm{O}_{12}$. More specifically, the atomic moments lie in the $x y$-plane rather than along [001] and the spin structure is non-collinear. The $x$ components adopt the same antiferromagnetic pattern seen in $\mathrm{ZrMn}_{2} \mathrm{Ge}_{4} \mathrm{O}_{12}$ but the $y$ components align in a ferromagnetic pattern. Overall, the magnetic structure is described by the magnetic space group Pb'an'(=Pc'n'a, \#50.6.382). The refined structural parameters are listed in Table 3 and selected bond lengths and bond angles are presented in Table 4. The atomic moments determined from data collected using a wavelength of $2.4397 \AA$ in fields of $0,3,6$ and 20 $\mathrm{kOe}$ at $1.6 \mathrm{~K}$ are listed in Table 5. As in the case of $\mathrm{ZrMn}_{2} \mathrm{Ge}_{4} \mathrm{O}_{12}$, the crystal structure did not change significantly when the field was applied. No magnetic Bragg scattering from $\mathrm{ZrCo}_{2} \mathrm{Ge}_{4} \mathrm{O}_{12}$ was visible in a diffraction pattern collected at $7 \mathrm{~K}$, see Figure 12 . However, it was still necessary to include the magnetically-ordered impurity. $\mathrm{CoGeO}_{3}$ can exist in two forms, monoclinic and orthorhombic, which have Néel temperatures of 35.8 and $33.0 \mathrm{~K}$, 
respectively ${ }^{26}$. Our refinements showed the impurity to be the orthorhombic form and a data set collected at $40 \mathrm{~K}$ could accordingly be analysed with the inclusion of only the main phase and a paramagnetic $\mathrm{CoGeO}_{3}$ impurity with a weight fraction of 4.4(2)\%, see Figure 12(c). The impurity concentration was fixed at this value in the analyses of all the neutron diffraction patterns collected from $\mathrm{ZrCo}_{2} \mathrm{Ge}_{4} \mathrm{O}_{12}$. We note that paramagnetic $\mathrm{CoGeO}_{3}$ gives rise to relatively weak Bragg peaks in both X-ray and neutron diffraction, see Figure 3, and in the antiferromagnetic phase the neutron diffraction pattern is dominated by the magnetic Bragg peak that occurs at $2 \theta=14.5^{\circ}$ when $\lambda=2.4397 \AA^{26}$.

Neutron diffraction data were collected on the intermediate composition $\mathrm{ZrMnCoGe}_{4} \mathrm{O}_{12}$ at 3 $\mathrm{K}$ and $20 \mathrm{~K}$. A $\mathrm{CoGeO}_{3}$ impurity was seen to be present at a level of $0.7(1)$ wt. \%. Additional Bragg scattering consistent with the presence of antiferromagnetic ordering in the main phase was clearly apparent in the data collected at the lower temperature. This scattering was consistent with the spin structure observed in $\mathrm{ZrCo}_{2} \mathrm{Ge}_{4} \mathrm{O}_{12}$ (Pb'a'n, \#50.6.382), see Figure 11, albeit with the ferromagnetic component in the ab-plane too small to be detected in our NPD data. The weak ferromagnetism allowed by this magnetic space group was however observed in the magnetometry data. The structural parameters derived from the data collected at $3 \mathrm{~K}$ using a wavelength of $1.622 \AA$ are presented in Table 3 and the observed and calculated diffraction patterns are shown in Figure 13; the bond lengths and bond angles are listed in Table 4.

In our collinear magnetic DFT calculations we considered the relative stability of A-type, Btype, C-type and G-type magnetic ordering for $\mathrm{ZrMn}_{2} \mathrm{Ge}_{4} \mathrm{O}_{12}$ and $\mathrm{ZrCo}_{2} \mathrm{Ge}_{4} \mathrm{O}_{12}{ }^{25}$; A-, C- and G-type result in antiferromagnetism whereas B-type ordering results in ferromagnetism, see Figure 14. We also considered additional structures, included in Figure 14, which were not included in the original classification by Wollan and Koehler; we shall refer to these as Stype and T-type ordering. The C-type structure was calculated to be the most stable for both compositions. The stabilities of the different ordering patterns relative to that of the C-type structure are listed in Table 6 and the values of the exchange constants calculated in the case of C-type ordering are listed in Table 7. The tabulated values relate to individual superexchange pathways between a pair of cations; they have not been adjusted to allow for the different multiplicities of the various intercation interactions. The two exchange constants, $\mathrm{J}_{3}$ and $\mathrm{J}_{4}$, that both relate to coupling between $\mathrm{NNN}$ along <101> correspond to the superexchange pathways $M-\mathrm{O} 1-\mathrm{Ge}-\mathrm{O} 1-M$ and $M-\mathrm{O} 2-\mathrm{Ge}-\mathrm{O} 2-M$, see Figure 2(b), respectively. The Weiss temperatures of $\mathrm{ZrMn}_{2} \mathrm{Ge}_{4} \mathrm{O}_{12}$ and $\mathrm{ZrCo}_{2} \mathrm{Ge}_{4} \mathrm{O}_{12}$ were calculated to be -12.62 and $-15.59 \mathrm{~K}$, respectively. 


\section{Discussion}

All the compounds studied are isostructural and the unit-cell volume decreases in a linear manner with increasing cobalt content, as is to be expected in view of the relative ionic radii of $\mathrm{Mn}^{2+}$ and $\mathrm{Co}^{2+27}$. The unit cell volume of each composition is $\sim 4.5 \%$ smaller than that of the analogous Ce-containing composition. Consideration of the data in Table 4 shows that the bond lengths in the two end members of the solid solution do not change significantly on cooling below room temperature. We note that, as in $\mathrm{CeMn}_{2} \mathrm{Ge}_{4} \mathrm{O}_{12}$ and $\mathrm{CeCo}_{2} \mathrm{Ge}_{4} \mathrm{O}_{12}$ but in contrast to $\mathrm{Y}_{2} \mathrm{CoGe}_{4} \mathrm{O}_{12}{ }^{23}$, there was no evidence for disorder on the oxide sublattices of $\mathrm{ZrMn}_{2} \mathrm{Ge}_{4} \mathrm{O}_{12}$ or $\mathrm{ZrCo}_{2} \mathrm{Ge}_{4} \mathrm{O}_{12}$. This is consistent with our previous suggestion that the oxide disorder is attributable to the disordered distribution of $\mathrm{Y}^{3+}$ and $\mathrm{Co}^{2+}$ over the $4 f$ sites in $\mathrm{Y}_{2} \mathrm{CoGe}_{4} \mathrm{O}_{12}$. The $\mathrm{Mn}^{2+}$ and $\mathrm{Co}^{2+}$ cations in $\mathrm{ZrMn}_{2} \mathrm{Ge}_{4} \mathrm{O}_{12}$ and $\mathrm{ZrCo}_{2} \mathrm{Ge}_{4} \mathrm{O}_{12}$ occupy a site with point symmetry $2 / m$ and the oxide ions to which they are coordinated therefore do not form a regular octahedron. In each case there are two long, trans bonds to O1, see Table 4, and four shorter, coplanar bonds to $\mathrm{O} 2$; the plane in which the latter lie is not perpendicular to the axis formed by the long bonds. The mean bond lengths in the $\mathrm{MnO}_{6}$ and $\mathrm{CoO}_{6}$ octahedra, 2.203 and $2.140 \AA$, are both shorter than those in the Ce analogues although the contraction, $\sim 1 \%$, is more marked in the case of the Mn-containing compound. The corresponding lengths in $\mathrm{MnO}$ and $\mathrm{CoO}$ are 2.223 and $2.132 \AA$ at room temperature ${ }^{28}$, suggesting that the $\mathrm{Mn}^{2+}$ cation in $\mathrm{ZrMn}_{2} \mathrm{Ge}_{4} \mathrm{O}_{12}$ might be in a compressed environment. However, a bondvalence calculation for the $\mathrm{Mn}^{2+}$ site resulted in a value of 2.04. The four $\mathrm{O} 2$ anions that coordinate the cation in the plane form a rectangle rather than a square, with $\mathrm{O} 2-\mathrm{O} 2$ distances of 3.301 and 2.652 $\AA$ at $3.5 \mathrm{~K}$ in the Mn-containing compound and 3.196 and 2.569 $\AA$ at $1.6 \mathrm{~K}$ in $\mathrm{ZrCo}_{2} \mathrm{Ge}_{4} \mathrm{O}_{12}$; the latter value is an unusually short $\mathrm{O}-\mathrm{O}$ distance. The $\mathrm{Zr}-\mathrm{O}$ distances within the square antiprism of oxide ions that surround the $2 b$ site in $\mathrm{ZrMn}_{2} \mathrm{Ge}_{4} \mathrm{O}_{12}$ and $\mathrm{ZrCo}_{2} \mathrm{Ge}_{4} \mathrm{O}_{12}$ are very similar to each other and also to the value of $2.224 \AA$ determined for 8-coordinate $\mathrm{Zr}^{4+}$ in cubic $\mathrm{ZrO}_{2}{ }^{29}$. The $\mathrm{O}-\mathrm{O}$ distances within the approximately square faces of the antiprism are $2.661 \AA$ in $\mathrm{ZrCo}_{2} \mathrm{Ge}_{4} \mathrm{O}_{12}$; the distances between anions in the opposing faces are alternately 2.801 and $2.569 \AA$, i.e. the $\mathrm{CoO}_{6}$ octahedra share their trans short edges with neighbouring $\mathrm{ZrO}_{8}$ antiprisms. Interestingly, the $\mathrm{O}-\mathrm{O}$ distance in $\mathrm{ZrO}_{2}$ is

also $2.568 \AA$. The $\mathrm{GeO}_{4}$ tetrahedra in both $\mathrm{ZrMn}_{2} \mathrm{Ge}_{4} \mathrm{O}_{12}$ and $\mathrm{ZrCo}_{2} \mathrm{Ge}_{4} \mathrm{O}_{12}$ show a considerable degree of distortion, as was also the case in $\mathrm{Y}_{2} \mathrm{CoGe}_{4} \mathrm{O}_{12}$. The longer $\mathrm{Ge}-\mathrm{O} 1$ bonds provide the connectivity between the four $\mathrm{GeO}_{4}$ tetrahedra that make up a $\mathrm{Ge}_{4} \mathrm{O}_{12}$ 
group whereas each $\mathrm{O} 2$ atom is bonded to only one germanium atom. The data in Table 4 show that the $\mathrm{Mn} / \mathrm{Co}-\mathrm{O}$ and $\mathrm{Zr}-\mathrm{O}$ bond lengths in $\mathrm{ZrMnCoGe}_{4} \mathrm{O}_{12}$ are, unsurprisingly, intermediate between those in the compositions $\mathrm{x}=0.0$ and 2.0, although those in the $\mathrm{GeO}_{4}$ tetrahedra are closer to those in the Mn-free composition.

The data presented in Table 2 and Figure 4 show that all the compositions in this solid solution can be modelled as Curie-Weiss paramagnets above $150 \mathrm{~K}$. The concentration of the $\mathrm{CoGeO}_{3}$ impurity is always too low for it to be detected in the magnetometry data. The negative values of the Weiss temperature, $\theta$, demonstrate that the dominant interatomic magnetic interactions are antiferromagnetic in nature. The measured Curie constant of $\mathrm{ZrMn}_{2} \mathrm{Ge}_{4} \mathrm{O}_{12}$ is in excellent agreement with the value calculated from the spin-only formula, as might be expected for the high-spin $\mathrm{d}^{5}$ cation, $\mathrm{Mn}^{2+}$. In the case of $\mathrm{ZrCo}_{2} \mathrm{Ge}_{4} \mathrm{O}_{12}$ the effective magnetic moment of $\mathrm{Co}^{2+}$ can be determined directly from the observed Curie constant and for the compositions containing both magnetic cations it can be calculated after subtracting the contribution from the spin-only $\mathrm{Mn}^{2+}$ cations. The values determined in this manner vary little with composition and they are always higher than the spin-only value for a high-spin $\mathrm{d}^{7}$ cation, implying that an orbital contribution to the moment is present. We shall return to this point below. All the compositions studied appear to show long-range magnetic order at $2 \mathrm{~K}$. The transition temperature, $\mathrm{T}_{\mathrm{C}}$, increases with increasing manganese content as was also the case in $\mathrm{CeMn}_{2-\mathrm{x}} \mathrm{Co}_{\mathrm{x}} \mathrm{Ge}_{4} \mathrm{O}_{12}$. We note that our calculations predict the interactions in $\mathrm{ZrCo}_{2} \mathrm{Ge}_{4} \mathrm{O}_{12}$ to be stronger than those in $\mathrm{ZrMn}_{2} \mathrm{Ge}_{4} \mathrm{O}_{12}$, perhaps because they could not take into account the non-collinear nature of the magnetic structure, see below. $\mathrm{Co}^{2+}-\mathrm{O}$ bonds are expected to be more covalent than $\mathrm{Mn}^{2+}$ - $\mathrm{O}$ bonds as a consequence of the smaller ionic radius of $\mathrm{Co}^{2+}$. In other solid solutions, for example $\mathrm{Mn}_{1-\mathrm{x}} \mathrm{Co}_{\mathrm{x}} \mathrm{O}^{4}$, the magnetic ordering temperature increases with increasing covalency. The trend observed in $\mathrm{ZrMn}_{2-\mathrm{x}} \mathrm{Co}_{\mathrm{x}} \mathrm{Ge}_{4} \mathrm{O}_{12}$ suggests that the degree of covalency in the metal to oxygen bonds does not control the ordering temperature in this system. The most obvious positive correlations are with the interatomic distances and the magnitude of the atomic moments. Despite the negative values of $\theta$, our data show that none of the compositions in this solid solution is a simple antiferromagnet. The dc susceptibility data and the function $\mathrm{M}(\mathrm{H})$, see Figure 4, indicate that they all show weak ferromagnetism below $\mathrm{T}_{\mathrm{C}}$. This is least obvious in the case of $\mathrm{ZrMn}_{2} \mathrm{Ge}_{4} \mathrm{O}_{12}$ but it is readily apparent when $\chi(\mathrm{T})$ is measured in a lower applied field, see Figure 6. The ac susceptibility data, see Figure 5, also demonstrate the presence of a ferromagnetic component in the magnetically-ordered phase; the imaginary component of the susceptibility is non-zero below $\mathrm{T}_{\mathrm{C}}$ and shows a maximum at a temperature that is 
independent of frequency. We note that the members of the solid solution become softer magnets, that is $\mathrm{H}_{\mathrm{C}}$ decreases, as the cobalt content increases, see Figure 4 and Table 2. Both the ac and the low-field dc susceptibility of $\mathrm{ZrMn}_{2} \mathrm{Ge}_{4} \mathrm{O}_{12}$ have an additional feature at $6 \mathrm{~K}$. We do not have an explanation for this at the present time; a sequence of neutron diffraction patterns collected at $3.75,4.75,6.75$ and $7.75 \mathrm{~K}$ did not reveal any change in the magnetic structure. Nor do we have an explanation for the local maximum observed in $\chi$ " of $\mathrm{ZrCo}_{2} \mathrm{Ge}_{4} \mathrm{O}_{12}$ at $3.5 \mathrm{~K}$, see Figure 5.

The magnetic structure of $\mathrm{ZrMn}_{2} \mathrm{Ge}_{4} \mathrm{O}_{12}$ determined by neutron diffraction, see Figure 8 , is that of a C-type antiferromagnet, as was that of $\mathrm{CeMn}_{2} \mathrm{Ge}_{4} \mathrm{O}_{12}{ }^{5}$. As described above, our magnetometry data show that a weak ferromagnetic component is present, but with a magnitude of $<0.05 \mu_{\mathrm{B}}$ that is apparently too weak to be detected by our diffraction experiment. The particular antiferromagnetic structure adopted can be rationalised by considering the superexchange pathways that are available to couple the cation moments, and we have previously given, in our account of $\mathrm{CeMn}_{2-\mathrm{x}} \mathrm{Co}_{\mathrm{x}} \mathrm{Ge}_{4} \mathrm{O}_{12}{ }^{5}$, a detailed, albeit qualitative, description of the possible interactions and predicted their relative strengths. We expect the arguments developed in that case also to be applicable in the case of $\mathrm{ZrMn}_{2}$ ${ }_{x} \mathrm{Co}_{\mathrm{x}} \mathrm{Ge}_{4} \mathrm{O}_{12}$. We argued that the $\mathrm{O}-\mathrm{O}$ distances in the structure were too long to allow strong $\mathrm{M}-\mathrm{O}-\mathrm{O}-\mathrm{M}$ coupling, and that $M-\mathrm{O}-\mathrm{Ge}-\mathrm{O}-M$ interactions would dominate. On this basis we predicted that, within a particular (001) cation layer, nearest-neighbour (NN) coupling would be stronger than next-nearest-neighbour (NNN) coupling and that the strongest interlayer coupling would be along $\langle 101\rangle$ rather than $\langle 001\rangle$, despite the direct $\mathrm{M}-$ $\mathrm{M}$ distance in the latter direction being the shortest in the structure. The <101> interaction was expected to be the strongest of all those present in the structure because the $M-\mathrm{O} 2-\mathrm{Ge}$ - $\mathrm{O} 2-M$ superexchange pathway, which plays a part in that interaction, is the shortest in the structure. The results of our DFT calculations are in good agreement with these qualitative predictions. They show, see Tables 6 and 7, that the superexchange along $M-\mathrm{O} 2-\mathrm{Ge}-\mathrm{O} 2$ - $M$, represented by $\mathrm{J}_{4}$, is the strongest magnetic interaction and that the C-type magnetic structure is the most stable of those considered. The magnetic structure of $\mathrm{ZrMn}_{2} \mathrm{Ge}_{4} \mathrm{O}_{12}$ drawn in Figure 8 is consistent with this account; each spin is aligned antiparallel to four NN spins in the same (001) sheet and antiparallel to eight <101> NNN spins in the sheets above and below, thus satisfying the strong $\mathrm{J}_{2}, \mathrm{~J}_{3}$ and $\mathrm{J}_{4}$ interactions. This necessitates ferromagnetic alignment of the spins along [001] which can be achieved because the antiferromagnetic coupling, represented by $\mathrm{J}_{1}$, in this direction is much weaker. Furthermore, the ferromagnetic coupling along [001] minimises dipolar repulsions within the structure. The magnitude of the 
ordered magnetic moment, 4.68(2) $\mu_{\mathrm{B}}$ per $\mathrm{Mn}^{2+}$ is lower than the maximum possible value, $\mathrm{g} S=5 \mu_{\mathrm{B}}$, as a consequence of covalency ${ }^{30}$ and the zero-point spin reduction. The observed value can be compared with that of $4.64 \mu_{\mathrm{B}}$ measured in $\mathrm{MnO}{ }^{31,32}$. As was the case in $\mathrm{CeMn}_{2} \mathrm{Ge}_{4} \mathrm{O}_{12}$, the application of a magnetic field of $30 \mathrm{kOe}$ reduced the ordered moment, presumably because the field was, to some extent, able to rotate the spins in the polycrystalline sample.

The magnetic structure of $\mathrm{ZrCo}_{2} \mathrm{Ge}_{4} \mathrm{O}_{12}$, see Figure 11, differs from that of the Mn-containing analogue in a number of ways. This is not surprising given that the two magnetic cations have different electronic ground states and consequently will experience different spin-lattice coupling interactions. The most striking differences are that the ordered moments in $\mathrm{ZrCo}_{2} \mathrm{Ge}_{4} \mathrm{O}_{12}$ lie perpendicular to [001], rather than parallel to it, and although the dominant [100] components adopt the same C-type antiferromagnet ordering pattern as was predicted by our calculations and seen in $\mathrm{ZrMn}_{2} \mathrm{Ge}_{4} \mathrm{O}_{12}$, the weaker [010] components align ferromagnetically in a B-type structure. The presence of a ferromagnetic component could not be predicted by our DFT calculations, which assumed a collinear spin structure, but it is consistent with the behaviour of $\chi(\mathrm{T})$ and $\mathrm{M}(\mathrm{H})$ seen in Figure 4 and the ferromagnetic component of $1.45 \mu_{\mathrm{B}}$ per $\mathrm{Co}^{2+}$ derived from the neutron data is in a good agreement with the saturation magnetisation determined by magnetometry. A comparable change in the spin direction was seen between $\mathrm{Sr}_{2} \mathrm{MnGe}_{2} \mathrm{O}_{7}$ and $\mathrm{Sr}_{2} \mathrm{CoGe}_{2} \mathrm{O}_{7}{ }^{33}$. The value of the ordered moment in $\mathrm{ZrCo}_{2} \mathrm{Ge}_{4} \mathrm{O}_{12}$ in the absence of a magnetic field is less than the spin-only value, $\mathrm{g} S=3 \mu_{\mathrm{B}}$, associated with a high-spin $\mathrm{d}^{7}$ cation. A covalent reduction would again be expected, but in this case the reduced value is surprising because the Curie constant measured above $150 \mathrm{~K}$ indicates that the moment has an orbital component that would be expected to raise the value observed by neutron diffraction above the spin-only value, despite the presence of covalency. We note that in the case of $\mathrm{CoO}$, which has an effective magnetic moment of $5.1 \mu_{\mathrm{B}}$ in the paramagnetic phase ${ }^{34}$, ordered moments in the range $3.35-3.8 \mu_{\mathrm{B}}$ have been determined by neutron diffraction ${ }^{1,35,36}$. Our data therefore suggest that either the orbital component of the magnetic moment does not order below $\mathrm{T}_{\mathrm{C}}$, or that it is quenched in the ferromagnetic phase. Similar behaviour has been seen in $\mathrm{Sr}_{2} \mathrm{CoGe}_{2} \mathrm{O}_{7}$ and $\mathrm{Co}(\mathrm{OH}) \mathrm{F}^{37}$ where it was attributed to chemical disorder and local distortions, neither of which are expected to be present in $\mathrm{ZrCo}_{2} \mathrm{Ge}_{4} \mathrm{O}_{12}$. The presence of an orbital contribution to the moment in the paramagnetic phase might be considered surprising in the light of the bond lengths listed in Table 4. The pseudo-tetragonal distortion of the $\mathrm{CoO}_{6}$ octahedra would be initially expected to remove the degeneracy of the electronic ground state of the $\mathrm{d}^{7}$ cation, see 
Figure 15(b), and hence quench the orbital angular momentum. In order to explain the presence of a large orbital contribution in the case of $\mathrm{Y}_{2} \mathrm{CoGe}_{4} \mathrm{O}_{12}$ we followed Smura et al ${ }^{38}$ in arguing that a sufficiently large distortion, with $(\mathrm{Co}-\mathrm{O} 1)_{\mathrm{ax}} /(\mathrm{Co}-\mathrm{O} 2)_{\mathrm{eq}}=1.116$ in the case of $\mathrm{Y}_{2} \mathrm{CoGe}_{4} \mathrm{O}_{12}$, can leave the $\mathrm{d}_{\mathrm{z}}^{2}$ orbital at the bottom of the $d$ manifold and thus restore the orbital contribution, see Figure 15(c). In the case of $\mathrm{ZrCo}_{2} \mathrm{Ge}_{4} \mathrm{O}_{12}(\mathrm{Co}-\mathrm{O} 1)_{\mathrm{ax}} /(\mathrm{Co}-\mathrm{O} 2)_{\mathrm{eq}}$ $=1.127$ and we therefore expect the same argument to be valid. However, the distortion of the octahedra is not purely tetragonal, as is demonstrated by the difference, $0.601 \AA$, between the $\mathrm{O} 2-\mathrm{O} 2$ ' and $\mathrm{O} 2-\mathrm{O} 2$ " distances. This additional strain will remove the degeneracy of the $d_{x z}$ and $d_{y z}$ orbitals that is required to maintain the orbital contribution, see Figure 15(d). We must assume that in the paramagnetic phase the splitting of these two orbitals is small compared to thermal energy and hence an orbital contribution is retained. However, below $3.5 \mathrm{~K}$, i.e. the Curie temperature, the splitting is presumably large compared to the thermal energy and so the orbital angular momentum is diminished. A significant increase in the ordered moment is observed in an applied field, see Table 5. We cannot deduce the cause of this from the available experimental data, but we note that $\mu_{\mathrm{B}} H / \mathrm{k}_{\mathrm{B}}=1.34 \mathrm{~K}$ for a field of 20 $\mathrm{kOe}$, a temperature that is comparable to both $\mathrm{T}_{\mathrm{C}}$ and the measuring temperature.

The zero-field magnetisation, $\sim 0.5 \mu_{\mathrm{B}}$ per formula unit, seen in $\mathrm{M}(\mathrm{H})$ for $\mathrm{ZrMnCoGe}_{4} \mathrm{O}_{12}$, see Figure 4, was too weak to be detected in our neutron diffraction experiment. The antiferromagnetic structure determined by diffraction is intermediate between those of the two end members in that the spin-ordering pattern is the same as in the case of $\mathrm{ZrMn}_{2} \mathrm{Ge}_{4} \mathrm{O}_{12}$ but the concentration of $\mathrm{Co}^{2+}$ is high enough for the anisotropy of that cation to select a different direction of alignment. Similar behaviour was seen in intermediate compositions in the solid solution $\mathrm{CeMn}_{2-\mathrm{x}} \mathrm{Co}_{\mathrm{x}} \mathrm{Ge}_{4} \mathrm{O}_{12}{ }^{5}$.

The most striking differences between the $\mathrm{Ce}^{4+}-$ and $\mathrm{Zr}^{4+}$ - containing solutions are seen in the $\mathrm{Mn}^{2+}$ - free, $\mathrm{x}=2.0$ end members. Whereas $\mathrm{ZrCo}_{2} \mathrm{Ge}_{4} \mathrm{O}_{12}$ is a weak ferromagnet, $\mathrm{CeCo}_{2} \mathrm{Ge}_{4} \mathrm{O}_{12}$ adopts an antiferromagnetic structure in a unit cell that is doubled along [001] compared to the structural unit cell. The atomic moments adopt a G-type ordering pattern along [100] with a weaker, A-type component along [010]. The adoption of a G-type structure indicates an increase in the relative strength of $J_{1}$ and $J_{2}$ but the A-type structure is consistent with strong $J_{3}$ and $J_{4}$ coupling. In an applied magnetic field $\mathrm{CeCo}_{2} \mathrm{Ge}_{4} \mathrm{O}_{12}$ undergoes a metamagnetic transition and becomes isostructural with $\mathrm{ZrCo}_{2} \mathrm{Ge}_{4} \mathrm{O}_{12}$. The neutron diffraction experiments described above did not identify any significant fielddependence in the structural behaviour of the latter. The reasons for this difference are not 
clear at the present time. The most obvious cause is the size difference between $\mathrm{Ce}^{4+}$ and $\mathrm{Zr}^{4+}$ and the subtle changes in the superexchange pathways that occur as a consequence. However, the differences in the detailed electronic structures of the two cations might also be important. The discovery of further compositions in which the unit-cell doubling is observed would facilitate the recognition of the key factors.

\section{Conclusions}

The magnetic properties of $\mathrm{ZrMn}_{2-\mathrm{x}} \mathrm{Co}_{\mathrm{x}} \mathrm{Ge}_{4} \mathrm{O}_{12}$ show a marked variation with composition as the isotropic $\mathrm{Mn}^{2+}$ cations are replaced by anisotropic $\mathrm{Co}^{2+}$ cations. The susceptibility of all compositions can be modelled using the Curie-Weiss law at temperatures above $150 \mathrm{~K}$ and they all undergo a transition to a magnetically ordered state in the temperature range $2 \leq \mathrm{T} / \mathrm{K}$ $\leq 10$. None of the compositions studied shows purely antiferromagnetic behaviour below the transition temperature, although in $\mathrm{ZrMn}_{2} \mathrm{Ge}_{4} \mathrm{O}_{12}$ the ferromagnetic component is too weak to be detected in magnetometry data collected in a field of $10 \mathrm{kOe}$ or in neutron powder diffraction data collected at $3.5 \mathrm{~K}$. A spontaneous magnetisation is clearly apparent in the magnetometry data collected on all the cobalt-containing samples but only in the case of $\mathrm{ZrCo}_{2} \mathrm{Ge}_{4} \mathrm{O}_{12}$ was the ferromagnetic component of the magnetic structure large enough to be detected by neutron diffraction. Although the behaviour of $\chi(T)$ in the paramagnetic region suggests the presence of an orbital contribution to the magnetic moment of $\mathrm{Co}^{2+}$, the ordered moment in the low-temperature phase suggests that no such component is present. This is consistent with the relatively low value of the coercive field, $\mathrm{H}_{\mathrm{C}}$. The spin-alignment axis varies with composition but, in contrast to the system $\mathrm{CeMn}_{2-\mathrm{x}} \mathrm{Co}_{\mathrm{x}} \mathrm{Ge}_{4} \mathrm{O}_{12}$, the experimentally-determined underlying antiferromagnetic component of the structure is always the same. The pseudo-cubic arrangement of the magnetic cations allows us to describe it as a C-type structure. It can be rationalised by considering the relative lengths of the $M-\mathrm{O}$

- $\mathrm{Ge}-\mathrm{O}-M$ superexchange pathways in the structure and is entirely consistent with the relative strengths of the exchange constants calculated by DFT methods. 


\section{References}

1. W. L. Roth, Physical Review, 1958, 110, 1333-1341.

2. R. A. Tahir-Kheli, H. B. Callen and H. Jarrett, J. Phys. Chem. Solids, 1960, 27, 23 32.

3. L. Bevaart, E. Frikkee, J. V. Lebesque and L. J. D. Jongh, Physical Review B, 1978, 18, 3376-3392.

4. $\quad$ D. A. O. Hope and A. K. Cheetham, Journal of Solid State Chemistry, 1988, 72, 4251.

5. D. Xu, M. Avdeev, P. D. Battle and X. Q. Liu, Inorg. Chem., 2017, 56, 2750-2762.

6. H. M. Rietveld, Journal of Applied Crystallography, 1969, 2, 65 - 71.

7. A. C. Larson and R. B. von Dreele, General Structural Analysis System (GSAS), Los Alamos National Laboratories, Report LAUR 86-748, 1990.

8. $\quad$ B. vanLaar and W. B. Yelon, J. Appl. Cryst., 1984, 17, 47-54.

9. G. Kresse and J. Furthmuller, Physical Review B, 1996, 54, 11169-11186.

10. G. Kresse and J. Furthmuller, Computational Materials Science, 1996, 6, 15-50.

11. G. Kresse and J. Hafner, Physical Review B, 1993, 47, 558-561.

12. G. Kresse and J. Hafner, Physical Review B, 1994, 49, 14251-14269.

13. G. Kresse and D. Joubert, Physical Review B, 1999, 59, 1758-1775.

14. J. P. Perdew, K. Burke and M. Ernzerhof, Physical Review Letters, 1996, 77, 38653868.

15. P. E. Blochl, Phys . Rev. B, 1994, 50, 17953-17979

16. H. J. Monkhorst and J. D. Pack, Physical Review B, 1976, 13, 5188-5192.

17. C. L. Fu and K. M. Ho, Physical Review B, 1983, 28, 5480-5486.

18. S. L. Dudarev, G. A. Botton, S. Y. Savrasov, C. J. Humphreys and A. P. Sutton, Physical Review B, 1998, 57, 1505-1509.

19. G. P. Francis and M. C. Payne, Journal of Physics-Condensed Matter, 1990, 2, 43954404.

20. H.-J. Koo, C. Lee and M.-H. Whangbo, Journal of Magnetism and Magnetic Materials, 2012, 324, 3716-3718.

21. L. Wang, T. Maxisch and G. Ceder, Physical Review B, 2006, 73, 195107. 
22. V. G. Zubkov, N. V. Tarakina, I. I. Leonidov, A. P. Tyutyunnik, L. L. Surat, M. A. Melkozerova, E. V. Zabolotskaya and D. G. Kellerman, Journal of Solid State Chemistry, 2010, 183, 1186-1193.

23. X.-Q. Liu, P. D. Battle, J. Ridout, D. Xu and S. Ramos, Journal of Solid State Chemistry, 2015, 228, 183-188.

24. K. Momma and F. Izumi, Journal of Applied Crystallography, 2008, 41, 653-658.

25. E. O. Wollan and W. C. Koehler, Physical Review, 1955, 100, 545-563.

26. G. J. Redhammer, A. Senyshyn, G. Tippelt, C. Pietzonka, G. Roth and G. Amthauer, Physics and Chemistry of Minerals, 2010, 37, 311-332.

27. R. D. Shannon, Acta Crystallographica, 1976, A 32, 751-767.

28. S. Sasaki, K. Fujino and Y. Takeuchi, Proceedings of the Japan Academy Series BPhysical and Biological Sciences, 1979, 55, 43-48.

29. D. N. Wang, Y. Q. Guo, K. M. Liang and K. Tao, Science in China Series aMathematics Physics Astronomy, 1999, 42, 80-86.

30. B. C. Tofield, J. de Physique, 1976, Coll C6, 539 - 569.

31. B. E. F. Fender, A. J. Jacobson and F. A. Wedgwood, Journal of Chemical Physics, 1968, 48, 990- 994.

32. A. J. Jacobson, B. C. Tofield and B. E. F. Fender, Journal of Physics C-Solid State Physics, 1973, 6, 1615-1622.

33. T. Endo, Y. Doi, Y. Hinatsu and K. Ohoyama, Inorganic Chemistry, 2012, 51, 35723578 .

34. N. Elliott, J. Chem. Phys., 1954, 22, 1924- 1925.

35. D. C. Khan and R. A. Erickson, Physical Review B-Solid State, 1970, 1, 2243- 2249.

36. B. vanLaar, Physical Review, 1965, 138, A584- A587.

37. H. Ben Yahia, M. Shikano, M. Tabuchi, H. Kobayashi, M. Avdeev, T. T. Tan, S. Liu and C. D. Ling, Inorganic Chemistry, 2014, 53, 365-374.

38. C. F. Smura, D. R. Parker, M. Zbiri, M. R. Johnson and Z. A. Gal, J. Amer. Chem. Soc., 2011, 133, 2691-2705. 


\section{Figure Captions}

Figure 1 Crystal structure of $\mathrm{ZrMn}_{2-\mathrm{x}} \mathrm{Co}_{\mathrm{x}} \mathrm{Ge}_{4} \mathrm{O}_{12}$ viewed along (a) [100] and (b) [001]. $\mathrm{Mn} / \mathrm{CoO}_{6}$ octahedra, $\mathrm{GeO}_{4}$ tetrahedra and $\mathrm{Zr}$ atoms are coloured magenta, green and blue, respectively.

Figure 2 (a) Schematic representation of superexchange interactions in $\mathrm{ZrMn}_{2-}$ ${ }_{x} \mathrm{Co}_{\mathrm{x}} \mathrm{Ge}_{4} \mathrm{O}_{12}$, (b) atomistic view showing the difference between $\mathrm{J}_{3}$ and $\mathrm{J}_{4}$; gold and red circles represent $\mathrm{O} 1$ and $\mathrm{O} 2$, respectively.

Figure 3 Observed (red) and calculated (green) $\mathrm{Cu} \mathrm{K} \mathrm{K}_{\alpha} \mathrm{X}$-ray diffraction profiles of $\mathrm{ZrCo}_{2} \mathrm{Ge}_{4} \mathrm{O}_{12}$. A difference curve is also shown. Vertical markers indicate reflection positions for both $\mathrm{ZrCo}_{2} \mathrm{Ge}_{4} \mathrm{O}_{12}$ (bottom) and the $\mathrm{CoGeO}_{3}$ impurity (top). The strongest reflection from the latter lies at $2 \theta \sim 35^{\circ}$, see inset.

Figure 4 Composition and temperature dependence of the dc molar magnetic susceptibility and the field dependence of the magnetisation per formula unit of $\mathrm{ZrMn}_{2-\mathrm{x}} \mathrm{Co}_{\mathrm{x}} \mathrm{Ge}_{4} \mathrm{O}_{12}$ The red line shows the result of fitting the susceptibility to the Curie-Weiss law.

Figure 5 Composition and temperature dependence of the real and imaginary components of the ac molar magnetic of $\mathrm{ZrMn}_{2-\mathrm{x}} \mathrm{Co}_{\mathrm{x}} \mathrm{Ge}_{4} \mathrm{O}_{12}$. A transition at $\sim 6$ $\mathrm{K}$ in $\mathrm{ZrMn}_{2} \mathrm{Ge}_{4} \mathrm{O}_{12}$ is indicated by an arrow.

Figure 6 Temperature dependence of the dc molar magnetic susceptibility of $\mathrm{ZrMn}_{2} \mathrm{Ge}_{4} \mathrm{O}_{12}$ (a) as a function of field and (b) in 10 Oe.. A transition at $\sim 6 \mathrm{~K}$ is indicated by an arrow.

Figure 7 Observed (red) and calculated (green) neutron diffraction profiles for $\mathrm{ZrMn}_{2} \mathrm{Ge}_{4} \mathrm{O}_{12}$ recorded using $\lambda=1.622 \AA$ at $3.5 \mathrm{~K}$; a difference curve is also shown. Vertical markers indicate the positions of both structural (lower) and magnetic (upper) reflections. 
Figure 8 The magnetic unit cell of $\mathrm{ZrMn}_{2} \mathrm{Ge}_{4} \mathrm{O}_{12}$; only $\mathrm{Mn}^{2+}$ cations are shown. Each is antiferromagnetically coupled to the four nearest-neighbour cations in the $x y$ plane.

Figure 9 Low-angle regions of the observed (red) and calculated (green) neutron diffraction profiles for $\mathrm{ZrMn}_{2} \mathrm{Ge}_{4} \mathrm{O}_{12}$ recorded using $\lambda=2.4397 \AA$ at (a) $3.5 \mathrm{~K}$ and (b) $15 \mathrm{~K}$; difference curves are also shown. In (a), vertical markers indicate the positions of both structural (lower) and magnetic (upper) reflections.

Figure 10 Observed (red) and calculated (green) neutron diffraction profiles for $\mathrm{ZrCo}_{2} \mathrm{Ge}_{4} \mathrm{O}_{12}$ recorded using $\lambda=1.622 \AA$ at $1.6 \mathrm{~K}$; a difference curve is also shown. Vertical markers indicate the reflection positions for, from top to bottom, $\mathrm{CoGeO}_{3}$ magnetic phase, $\mathrm{ZrCo}_{2} \mathrm{Ge}_{4} \mathrm{O}_{12}$ magnetic phase, $\mathrm{CoGeO}_{3}$ crystal structure and $\mathrm{ZrCo}_{2} \mathrm{Ge}_{4} \mathrm{O}_{12}$ crystal structure.

Figure 11 The magnetic unit cell of $\mathrm{ZrCo}_{2} \mathrm{Ge}_{4} \mathrm{O}_{12}$; only $\mathrm{Co}^{2+}$ cations are shown.

Figure 12 Low-angle regions of the observed (red) and calculated (green) neutron diffraction profiles for $\mathrm{ZrCo}_{2} \mathrm{Ge}_{4} \mathrm{O}_{12}$ recorded using $\lambda=2.4397 \AA$ at (a) $1.6 \mathrm{~K}$ (b) $7 \mathrm{~K}$ and (c) $40 \mathrm{~K}$; difference curves are also shown. Vertical markers in (a) indicate the reflection positions for, from top to bottom, $\mathrm{CoGeO}_{3}$ magnetic phase, $\mathrm{ZrCo}_{2} \mathrm{Ge}_{4} \mathrm{O}_{12}$ magnetic phase, $\mathrm{CoGeO}_{3}$ crystal structure and $\mathrm{ZrCo}_{2} \mathrm{Ge}_{4} \mathrm{O}_{12}$ crystal structure.

Figure 13 Observed (red) and calculated (green) neutron diffraction profiles for $\mathrm{ZrMnCoGe}_{4} \mathrm{O}_{12}$ recorded using $\lambda=1.622 \AA$ at $3 \mathrm{~K}$; a difference curve is also shown. Vertical markers indicate the reflection positions for, from top to bottom, $\mathrm{CoGeO}_{3}$ magnetic phase, $\mathrm{CoGeO}_{3}$ crystal structure, $\mathrm{ZrMnCoGe}_{4} \mathrm{O}_{12}$ magnetic phase and $\mathrm{ZrCo}_{2} \mathrm{Ge}_{4} \mathrm{O}_{12}$ crystal structure.

Figure 14 Magnetic structures considered in the DFT calculations. Blue and magenta circles represent spin-up and spin-down cations. The cell (c) used in the 
calculations is related to the structural unit cell as follows: $\mathbf{a}_{\mathrm{c}}=2 \mathbf{a}, \mathbf{b}_{\mathrm{c}}=\mathbf{b}, \mathbf{c}_{\mathrm{c}}=$ $\mathbf{a}+2 \mathbf{c}$

Figure 15 The crystal field splitting of the $d$ orbitals for six-coordinate $\mathrm{Co}^{2+}$ in (a) a regular octahedron (b) an octahedron with a small tetragonal elongation (c) an octahedron with a large tetragonal elongation and (d) an octahedron with a monoclinic distortion in addition to a large tetragonal elongation. 
Table 1

Unit cell parameters of $\mathrm{ZrMn}_{2-\mathrm{x}} \mathrm{Co}_{\mathrm{x}} \mathrm{Ge}_{4} \mathrm{O}_{12}$ at room temperature deduced from XRPD

\begin{tabular}{llllll}
\hline & \multicolumn{5}{c}{$\mathrm{x}$} \\
& \multicolumn{1}{c}{0} & \multicolumn{1}{c}{0.5} & \multicolumn{1}{c}{1.0} & \multicolumn{1}{c}{1.5} & \multicolumn{1}{c}{2} \\
\hline $\mathrm{a} / \AA$ & $9.6560(1)$ & $9.6302(1)$ & $9.6053(1)$ & $9.5799(1)$ & $9.5494(2)$ \\
$\mathrm{c} / \AA$ & $4.8636(1)$ & $4.8436(1)$ & $4.8244(1)$ & $4.8047(1)$ & $4.7838(2)$ \\
$\mathrm{V} / \AA^{3}$ & $453.473(5)$ & $449.208(6)$ & $445.104(6)$ & $440.948(7)$ & $436.24(2)$ \\
$\mathrm{R}_{\mathrm{wp}} / \%$ & 7.1 & 5.4 & 4.4 & 3.7 & 5.7 \\
$\chi^{2}$ & 1.84 & 1.70 & 1.57 & 1.44 & 1.12 \\
\hline
\end{tabular}

Space group $P 4 / n b m, Z=2$

Table 2

Magnetic parameters of $\mathrm{ZrMn}_{2-\mathrm{x}} \mathrm{Co}_{\mathrm{x}} \mathrm{Ge}_{4} \mathrm{O}_{12}$

\begin{tabular}{llllll}
\hline & \multicolumn{5}{c}{$\mathrm{x}$} \\
& \multicolumn{1}{c}{0} & \multicolumn{1}{c}{0.5} & \multicolumn{1}{c}{1.0} & \multicolumn{1}{c}{1.5} & \multicolumn{1}{c}{2} \\
\hline $\mathrm{C}_{\mathrm{m}}$ & $8.696(1)$ & $8.332(6)$ & $7.743(1)$ & $7.586(1)$ & $7.186(2)$ \\
$\theta / \mathrm{K}$ & $-11.38(2)$ & $-14.74(2)$ & $-17.50(2)$ & $-21.96(2)$ & $-15.93(2)$ \\
$\mu_{\mathrm{eff}}(\mathrm{Co})^{*}$ & $5.90^{\$}$ & 5.37 & 5.36 & 5.37 & 5.36 \\
$\mathrm{M}_{\mathrm{R}} / \mu_{\text {B }}$ per f.u. & - & 0.48 & 0.78 & 0.80 & 0.068 \\
$\mathrm{H}_{\mathrm{C}} / \mathrm{Oe}$ & - & 893 & 786 & 261 & 10.6 \\
$\mathrm{~T}_{\mathrm{C}} / \mathrm{K}$ & 8.0 & 6.7 & 6.0 & 5.2 & 3.5 \\
\hline
\end{tabular}

${ }^{\$} \mu_{\text {eff }}(\mathrm{Mn})$

*calculated for $0.5 \leq$ x 1.5 assuming that $\mu_{\text {eff }}(\mathrm{Mn})=5.90$ 


\section{Table 3}

Structural parameters of $\mathrm{ZrMn}_{2-\mathrm{x}} \mathrm{Co}_{\mathrm{x}} \mathrm{Ge}_{4} \mathrm{O}_{12}$ derived from neutron diffraction data $(\lambda=1.622$ $\AA$ ) as a function of composition and temperature

\begin{tabular}{|c|c|c|c|c|c|c|}
\hline & & \multicolumn{5}{|c|}{$x, T$} \\
\hline & & $0.0^{\dagger}, 3 \mathrm{~K}$ & $0.0^{\dagger}, 300 \mathrm{~K}$ & $1.0^{\ddagger}, 3 \mathrm{~K}$ & $2.0,3 \mathrm{~K}$ & $2.0,300 \mathrm{~K}$ \\
\hline $\mathrm{Zr}$ & $U_{\text {iso }} / \AA^{2}$ & $0.0020(2)$ & $0.0037(4)$ & $0.0020(2)$ & $0.0028(3)$ & $0.0037(4)$ \\
\hline $\mathrm{Mn} / \mathrm{Co}$ & $U_{\text {iso }} / \AA^{2}$ & $0.0052(5)$ & $0.0090(5)$ & $0.0039(4)$ & $0.0023(4)$ & $0.0078(5)$ \\
\hline \multirow[t]{2}{*}{$\mathrm{Ge}$} & $x$ & $0.5161(1)$ & $0.5160(1)$ & $0.5169(1)$ & $0.5172(1)$ & $0.5169(1)$ \\
\hline & $U_{\text {iso }} / \AA^{2}$ & $0.0014(1)$ & $0.0031(2)$ & $0.0012(2)$ & $0.0012(2)$ & $0.0026(2)$ \\
\hline \multirow[t]{3}{*}{$\mathrm{O} 1$} & $x$ & $\begin{array}{c}- \\
0.3733(1)\end{array}$ & $-0.3727(1)$ & $-0.3726(1)$ & $-0.3724(1)$ & $-0.3719(1)$ \\
\hline & $z$ & $0.1651(2)$ & $0.1638(3)$ & $0.1693(3)$ & $0.1755(4)$ & $0.1732(4)$ \\
\hline & $U_{\text {iso }} / \AA^{2}$ & $0.0013(3)$ & $0.0041(3)$ & $0.0032(3)$ & $0.0030(3)$ & $0.0045(3)$ \\
\hline \multirow[t]{4}{*}{$\mathrm{O} 2$} & $x$ & $0.1687(1)$ & $0.1687(1)$ & $0.1659(1)$ & $0.1633(2)$ & $0.1638(2)$ \\
\hline & $y$ & $0.0732(1)$ & $0.0732(1)$ & $0.0733(1)$ & $0.0730(2)$ & $0.0733(2)$ \\
\hline & $z$ & $0.2622(2)$ & $0.2622(2)$ & $0.2630(2)$ & $0.2636(2)$ & $0.2643(3)$ \\
\hline & $U_{\text {iso }} / \AA^{2}$ & $0.0028(3)$ & $0.0038(2)$ & $0.0022(4)$ & $0.0022(4)$ & $0.0039(2)$ \\
\hline$a / \AA ̊$ & & $9.6502(1)$ & $9.6532(1)$ & $9.5970(1)$ & $9.5477(1)$ & $9.5526(1)$ \\
\hline$c / \AA ̊$ & & $4.8567(1)$ & $4.8623(1)$ & $4.8165(1)$ & 4.7791(1) & $4.7850(1)$ \\
\hline$V / \AA^{3}$ & & $452.28(1)$ & $453.09(1)$ & 443.61(1) & $435.66(1)$ & $435.66(2)$ \\
\hline $\mathrm{R}_{\mathrm{wpr}}$ & & $4.65 \%$ & $4.94 \%$ & $4.82 \%$ & $4.09 \%$ & $5.87 \%$ \\
\hline$\chi^{2}$ & & 6.569 & 2.430 & 4.459 & 3.170 & 3.241 \\
\hline
\end{tabular}

Space group P4/nbm (No. 125), Z $=2$ with $\mathrm{Zr}$ on $2 b(1 / 4,1 / 4,1 / 2) ; \mathrm{Mn} / \mathrm{Co}$ on $4 f(0,0,1 / 2) ;$ Ge on $8 k(x, 1 / 4,0)$; O1 on $8 m(x,-x, \mathrm{z})$; O 2 on $16 n(x, y, z)$

${ }^{\dagger}$ Contains 4.4(2) wt $\% \mathrm{CoGeO}_{3}$

$\$$ Contains $0.7(1)$ wt $\% \mathrm{CoGeO}_{3}$ 


\section{Table 4}

Bond lengths ( $\mathrm{A}$ ) and bond angles (degrees) in $\mathrm{ZrMn}_{2-\mathrm{x}} \mathrm{Co}_{\mathrm{x}} \mathrm{Ge}_{4} \mathrm{O}_{12}$ as a function of composition and temperature

\begin{tabular}{|c|c|c|c|c|c|}
\hline & \multicolumn{5}{|c|}{$x, T$} \\
\hline & $0.0,3 \mathrm{~K}$ & $0.0,300 \mathrm{~K}$ & $1.0,3 \mathrm{~K}$ & $2.0,3 \mathrm{~K}$ & $2.0,300 \mathrm{~K}$ \\
\hline $\mathrm{Zr}-\mathrm{O} 2 \times 8$ & $2.205(1)$ & $2.206(1)$ & $2.198(1)$ & $2.194(1)$ & $2.191(2)$ \\
\hline $\mathrm{Mn} / \mathrm{Co}-\mathrm{O} 1 \times 2$ & $2.374(1)$ & $2.386(2)$ & $2.351(2)$ & $2.320(1)$ & $2.332(2)$ \\
\hline $\mathrm{Mn} / \mathrm{Co}-\mathrm{O} 2 \times 4$ & $2.117(1)$ & $2.119(1)$ & $2.082(1)$ & $2.050(1)$ & $2.052(2)$ \\
\hline $\mathrm{O} 2-\mathrm{O} 2{ }^{\prime} *$ & $3.301(1)$ & $3.302(1)$ & $3.247(2)$ & $3.196(1)$ & $3.203(2)$ \\
\hline $\mathrm{O} 2-\mathrm{O} 2 ” *$ & $2.652(1)$ & $2.655(1)$ & $2.606(2)$ & $2.569(1)$ & $2.565(2)$ \\
\hline $\mathrm{Ge}-\mathrm{O} 1 \times 2$ & $1.788(1)$ & $1.787(1)$ & $1.782(1)$ & $1.782(1)$ & $1.781(1)$ \\
\hline $\mathrm{Ge}-\mathrm{O} 2 \times 2$ & $1.726(1)$ & $1.727(1)$ & $1.734(1)$ & $1.735(1)$ & $1.738(2)$ \\
\hline $\mathrm{O} 2-\mathrm{Mn} / \mathrm{Co}-\mathrm{O} 2$ ' & $102.45(5)$ & $102.42(6)$ & $102.50(6)$ & $102.41(4)$ & 102.61(9) \\
\hline $\mathrm{O} 2-\mathrm{Mn} / \mathrm{Co}-\mathrm{O} 2 ”$ & $77.55(5)$ & $77.58(6)$ & $77.50(6)$ & $77.59(4)$ & 77.39(9) \\
\hline $\mathrm{O} 1-\mathrm{Mn} / \mathrm{Co}-\mathrm{O} 2$ & $81.40(4)$ & $81.38(4)$ & $81.41(4)$ & $81.54(4)$ & $81.51(6)$ \\
\hline $\mathrm{O} 1-\mathrm{Mn} / \mathrm{Co}-\mathrm{O} 2 ”$ & $98.60(4)$ & $98.62(4)$ & $98.59(4)$ & $98.46(4)$ & $98.49(6)$ \\
\hline O1-Ge-O1 & $106.73(10)$ & $106.04(11)$ & $106.89(11)$ & $107.46(10)$ & $106.77(16)$ \\
\hline $\mathrm{O} 1-\mathrm{Ge}-\mathrm{O} 2$ & $105.63(5)$ & 105.78(5) & 105.67(6) & $105.34(5)$ & $105.49(9)$ \\
\hline $\mathrm{O} 1-\mathrm{Ge}-\mathrm{O} 2$ & 109.04(7) & $109.13(7)$ & $108.93(8)$ & $108.85(7)$ & $108.93(11)$ \\
\hline $\mathrm{O} 2-\mathrm{Ge}-\mathrm{O} 2$ & $120.12(7)$ & $120.20(8)$ & $120.11(8)$ & $120.43(7)$ & $120.55(11)$ \\
\hline
\end{tabular}

* distances within the equatorial plane of the $(\mathrm{Mn} / \mathrm{Co}) \mathrm{O}_{6}$ octahedra 
Table 5

Field dependence of the ordered magnetic moment of $\mathrm{Co}^{2+}$ in $\mathrm{Zr}_{2} \mathrm{Co}_{2} \mathrm{Ge}_{4} \mathrm{O}_{12}$ at $1.6 \mathrm{~K}$

\begin{tabular}{ccccc}
\hline & \multicolumn{5}{c}{$\mathrm{H} / \mathrm{kOe}$} \\
& 0 & 3 & 6 & 20 \\
\hline$M_{x}$ & $2.10(5)$ & $2.21(5)$ & $2.33(4)$ & $2.30(5)$ \\
$M_{y}$ & $1.45(8)$ & $1.43(9)$ & $1.73(7)$ & $2.07(6)$ \\
$M$ & $2.55(7)$ & $2.63(7)$ & $2.90(5)$ & $3.09(6)$ \\
\hline
\end{tabular}

\section{Table 6}

Relative stabilities $\left(\mathrm{K}^{-1}\right)$ of different magnetic structures for $\mathrm{ZrM}_{2} \mathrm{Ge}_{4} \mathrm{O}_{12}(M=\mathrm{Mn}$, Co)

\begin{tabular}{lll}
\hline Structure type & \multicolumn{2}{c}{$M$} \\
& $\mathrm{Mn}(\mathrm{U}-\mathrm{J}=5 \mathrm{eV})$ & $\mathrm{Co}(\mathrm{U}-\mathrm{J}=4 \mathrm{eV})$ \\
\hline $\mathrm{A}$ & 4.993 & 5.282 \\
$\mathrm{~B}$ & 24.654 & 28.178 \\
$\mathrm{C}$ & 0 & 0 \\
$\mathrm{G}$ & 15.989 & 23.932 \\
$\mathrm{~S}$ & 9.943 & 14.204 \\
$\mathrm{~T}$ & 9.031 & 10.196 \\
\hline
\end{tabular}

\section{Table 7}

Calculated exchange constants of $\mathrm{ZrM}_{2} \mathrm{Ge}_{4} \mathrm{O}_{12}(M=\mathrm{Mn}, \mathrm{Co})$

\begin{tabular}{lll}
\hline & & $M$ \\
& Mn $(\mathrm{U}-\mathrm{J}=5 \mathrm{eV})$ & $\mathrm{Co}(\mathrm{U}-\mathrm{J}=4 \mathrm{eV})$ \\
\hline $\mathrm{J}_{1} / \mathrm{K}$ & -0.147 & 0.115 \\
$\mathrm{~J}_{2} / \mathrm{K}$ & -0.273 & -0.529 \\
$\mathrm{~J}_{3} / \mathrm{K}$ & -0.188 & -0.423 \\
$\mathrm{~J}_{4} / \mathrm{K}$ & -0.525 & -2.179 \\
$\mathrm{~J}_{5+6} / \mathrm{K}$ & -0.0219 & -0.0448 \\
\hline
\end{tabular}




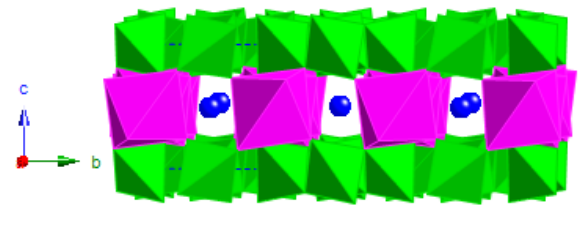

(a)

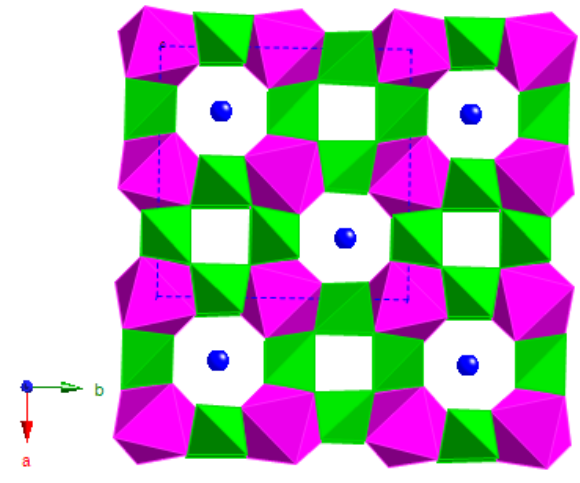

(b)

Figure 1

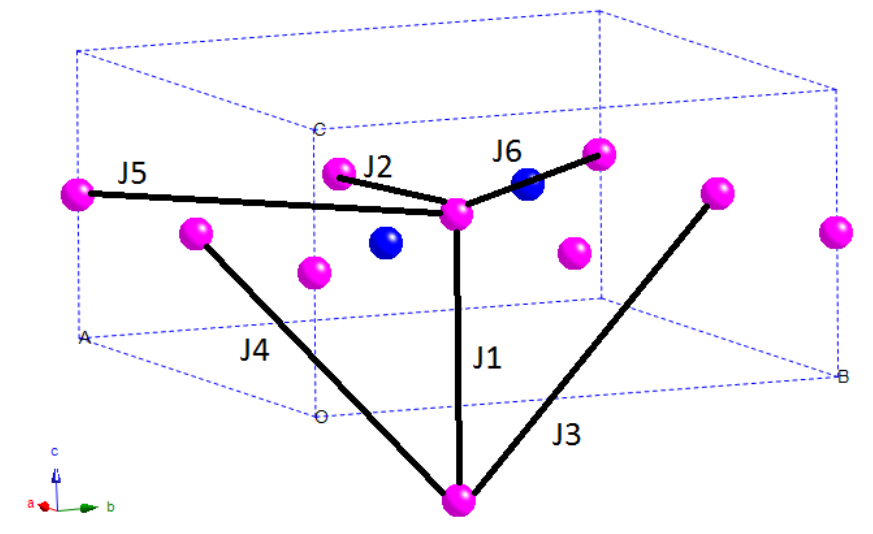

(a)

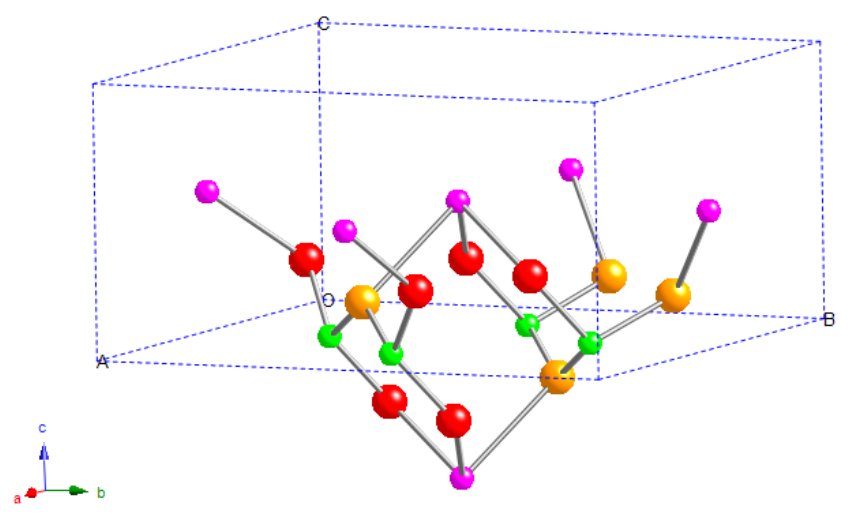

(b)

Figure 2 


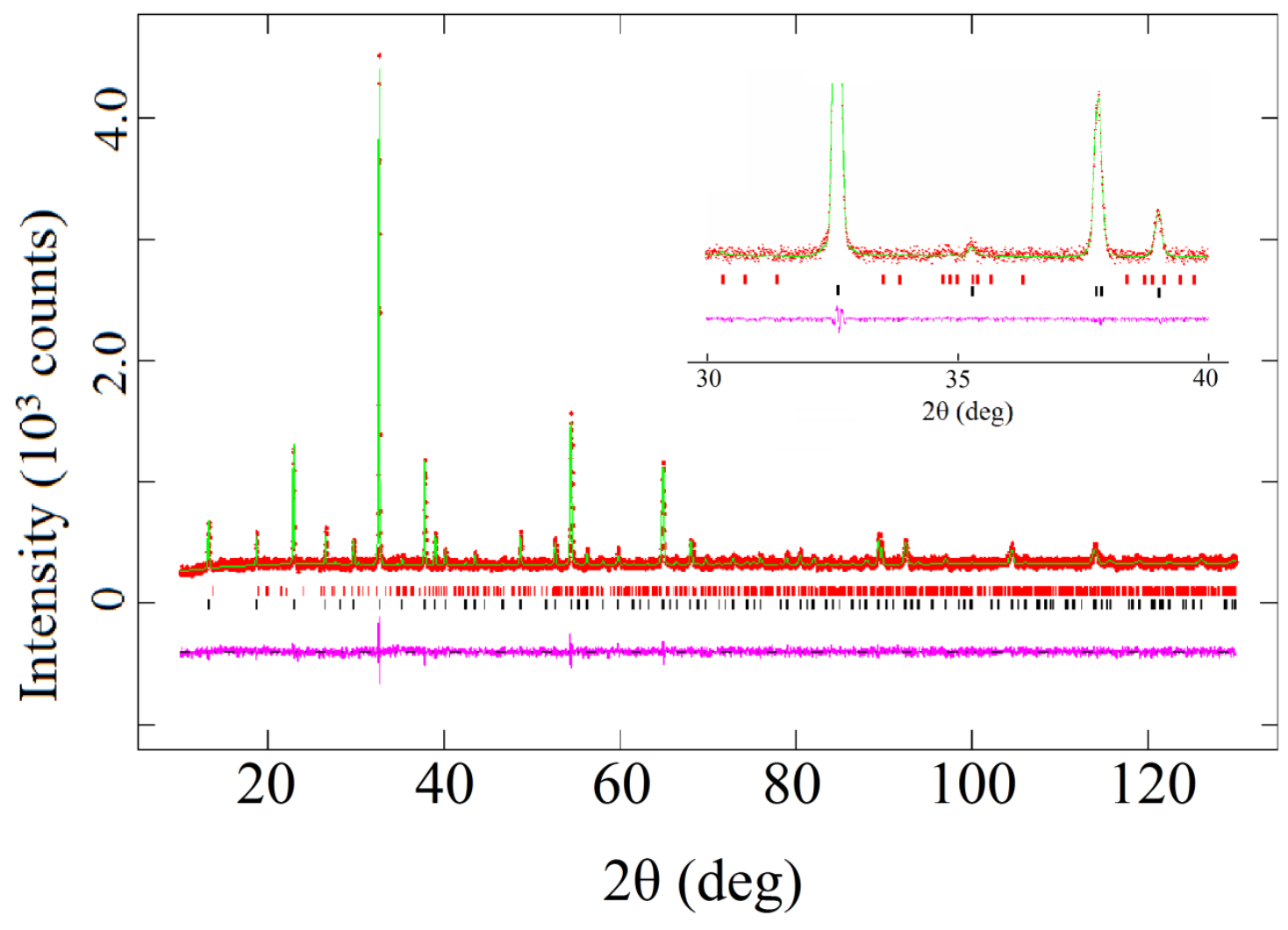

Figure 3 


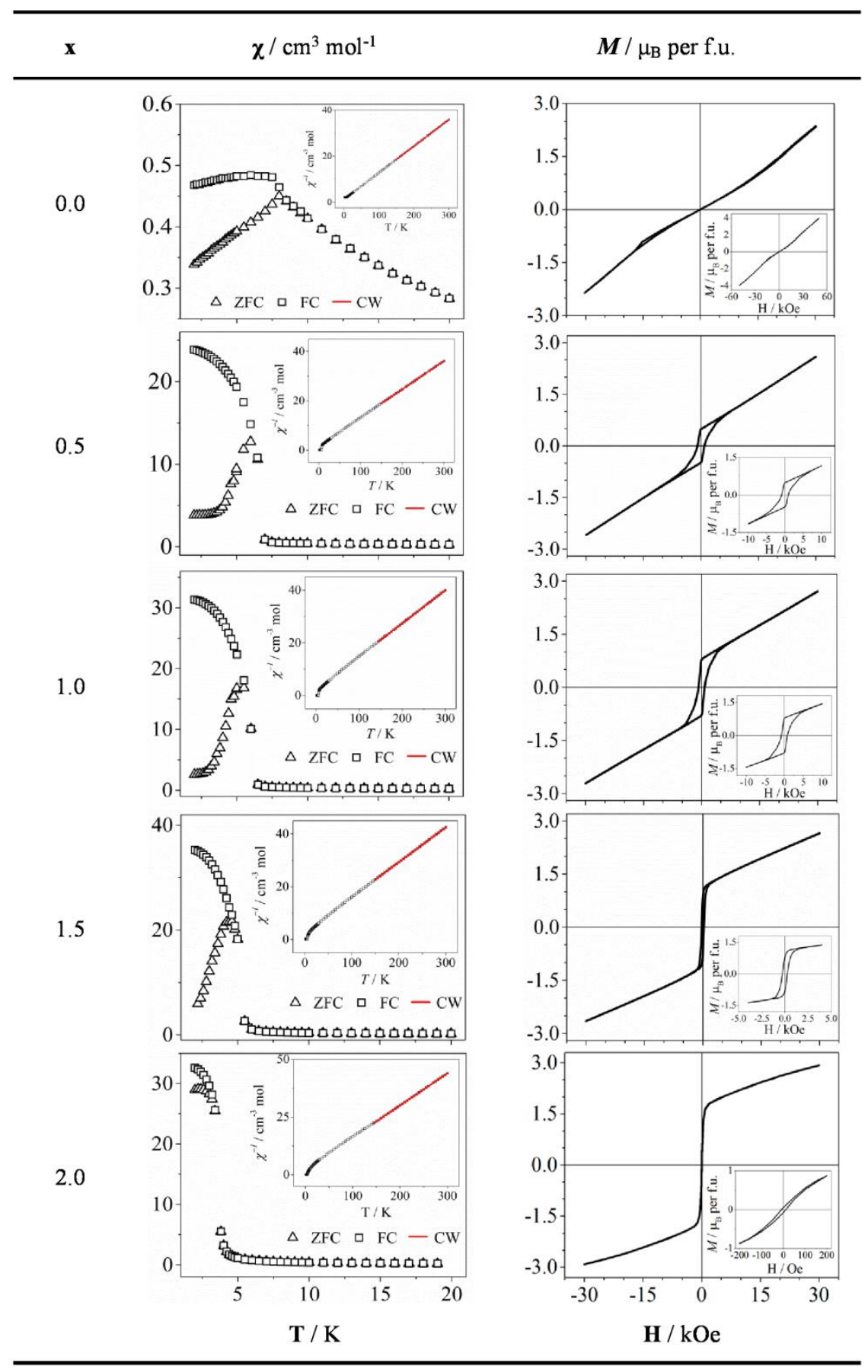

Figure 4 


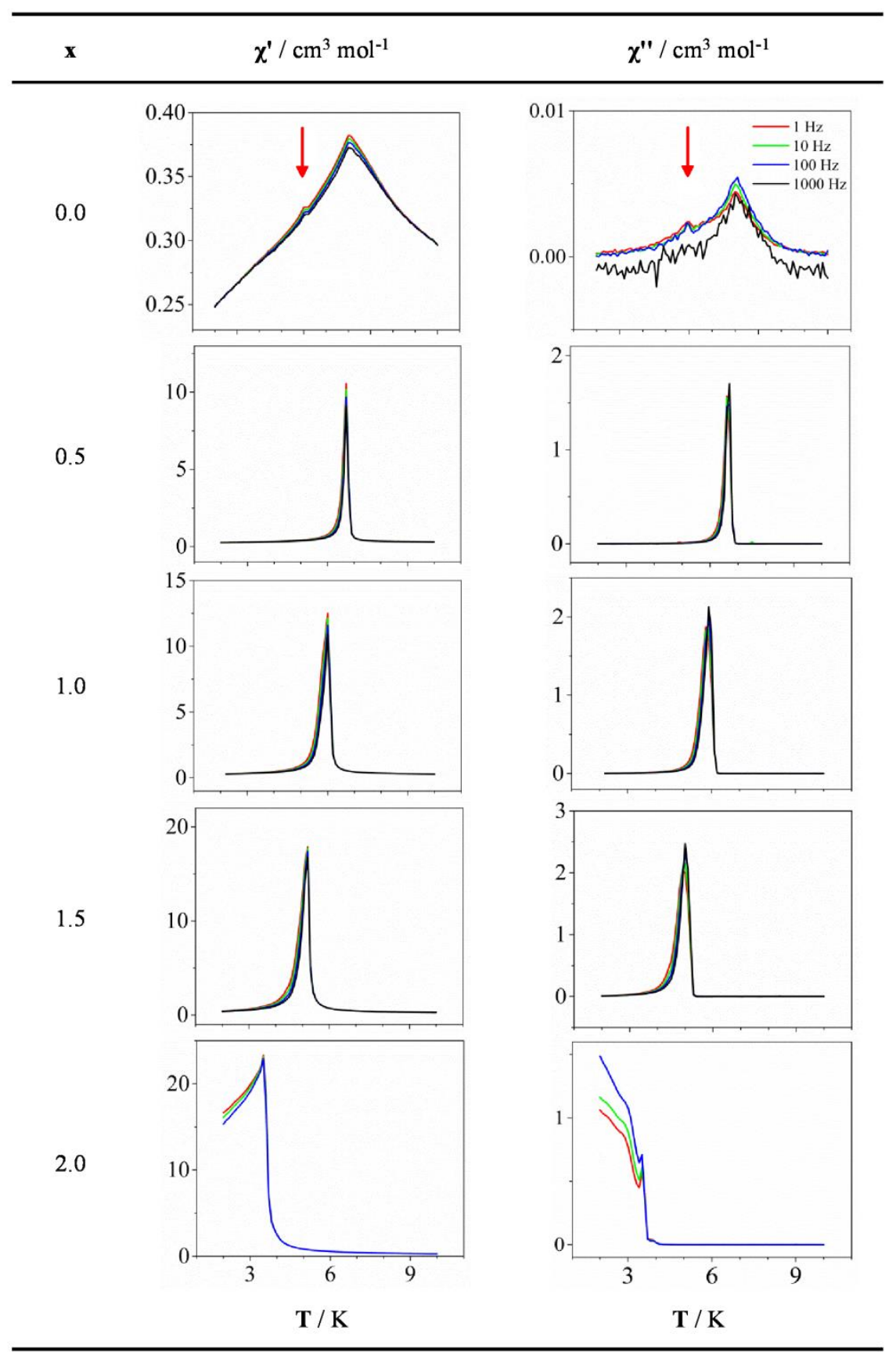

Figure 5

(a) 


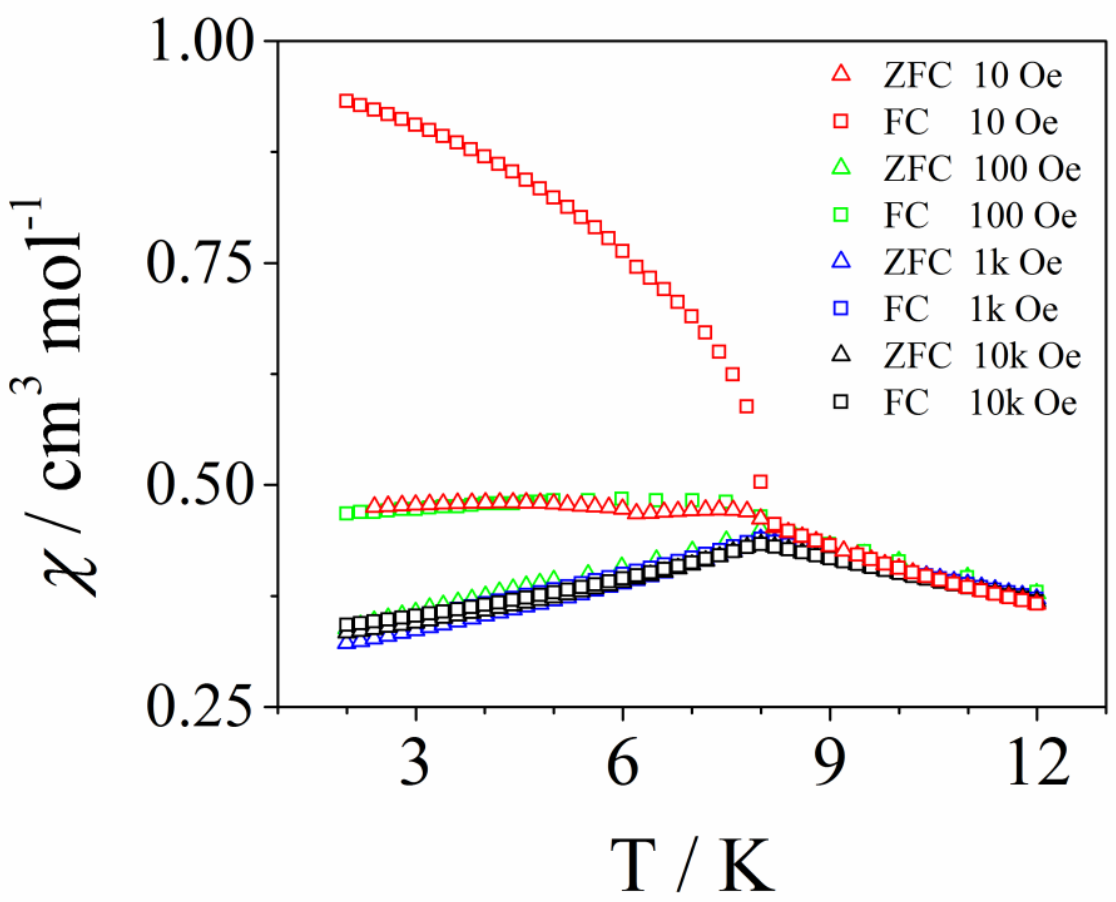

(b)

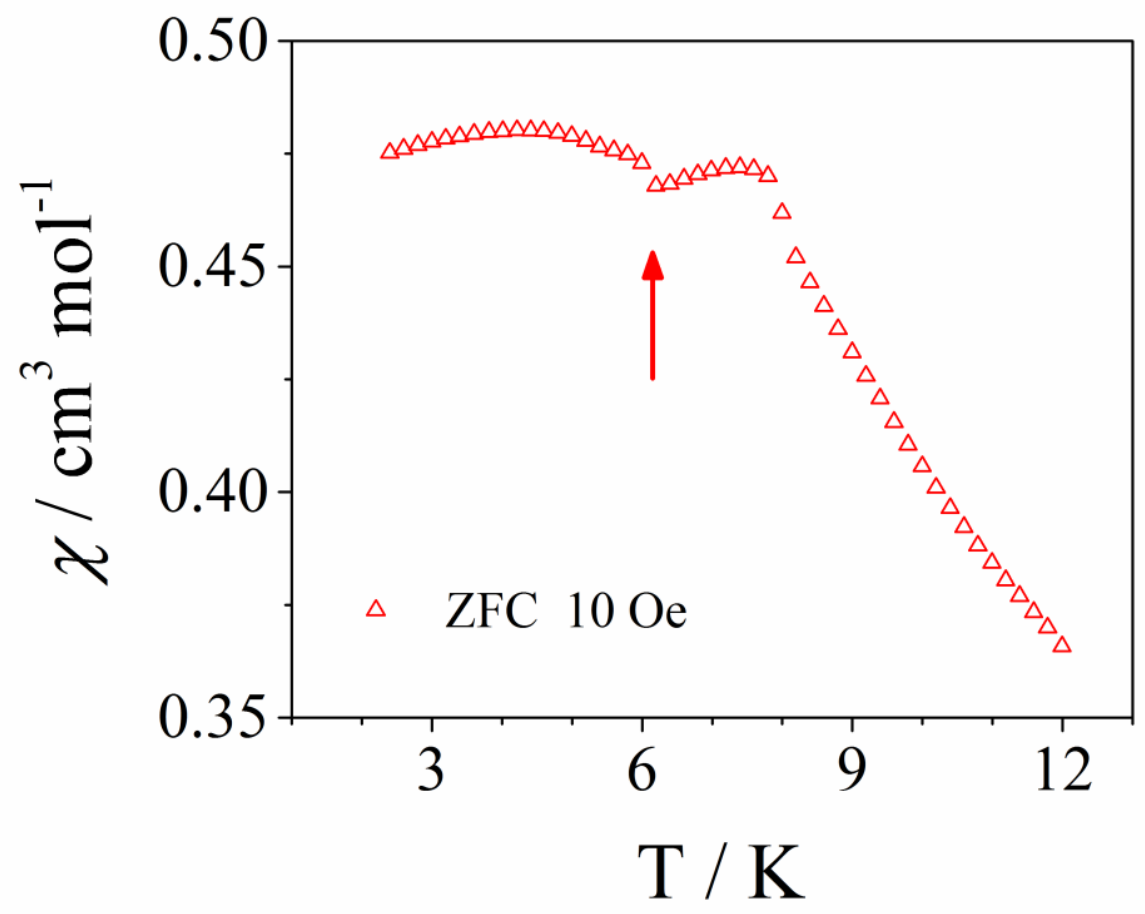

Figure 6 


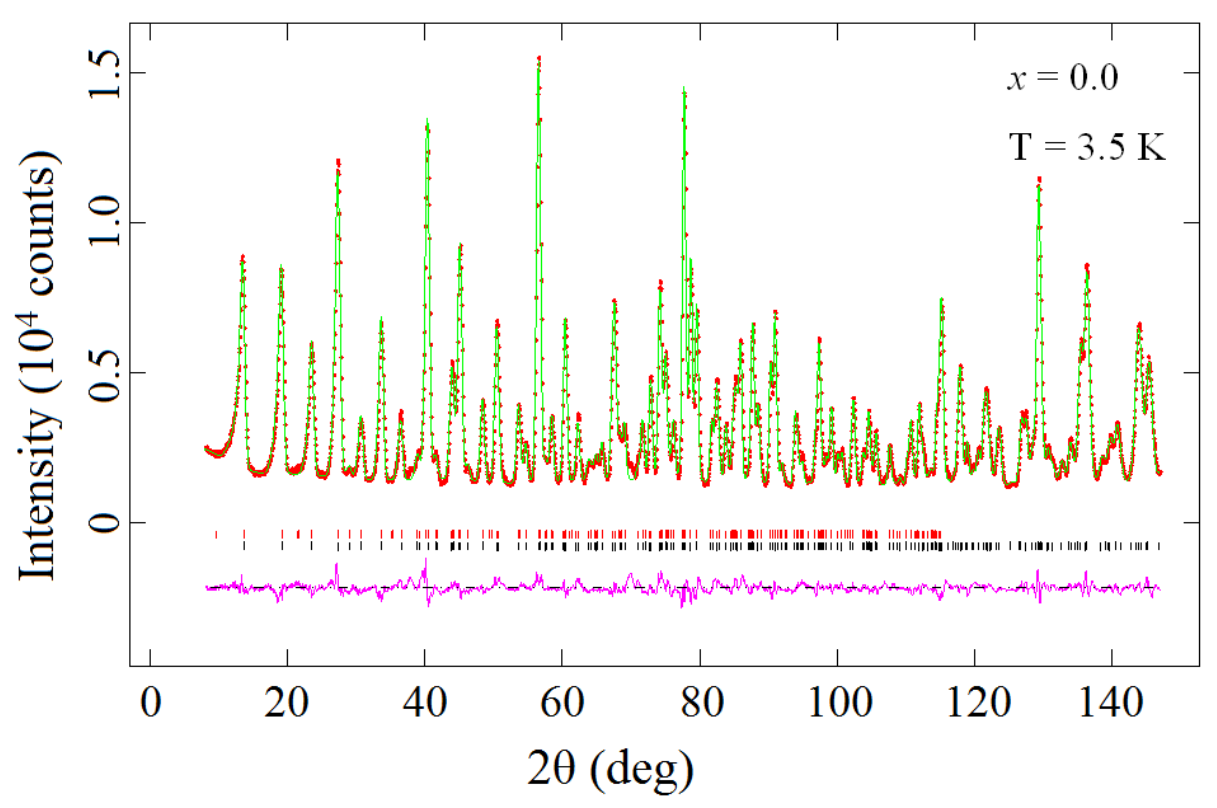

Figure 7

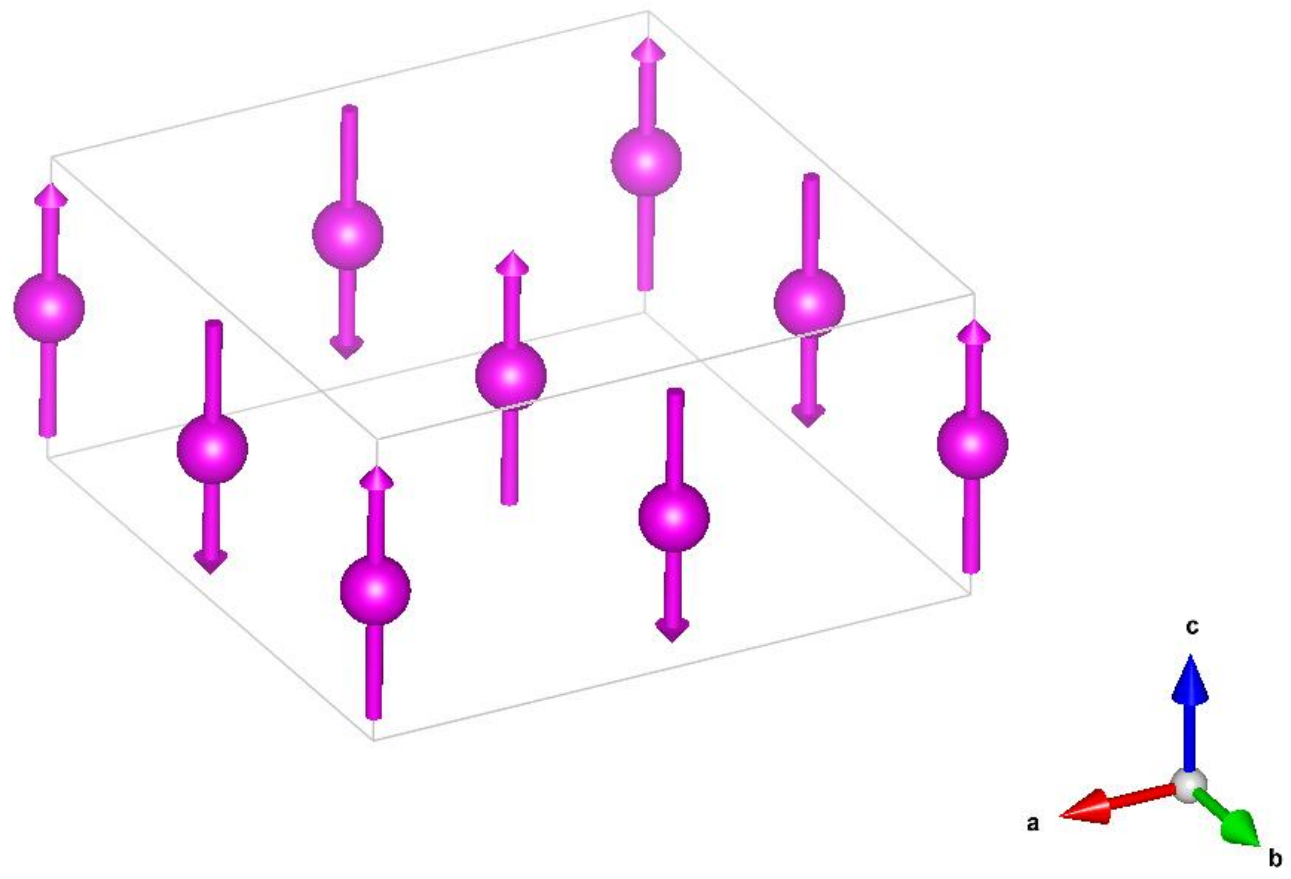

Figure 8 
(a)

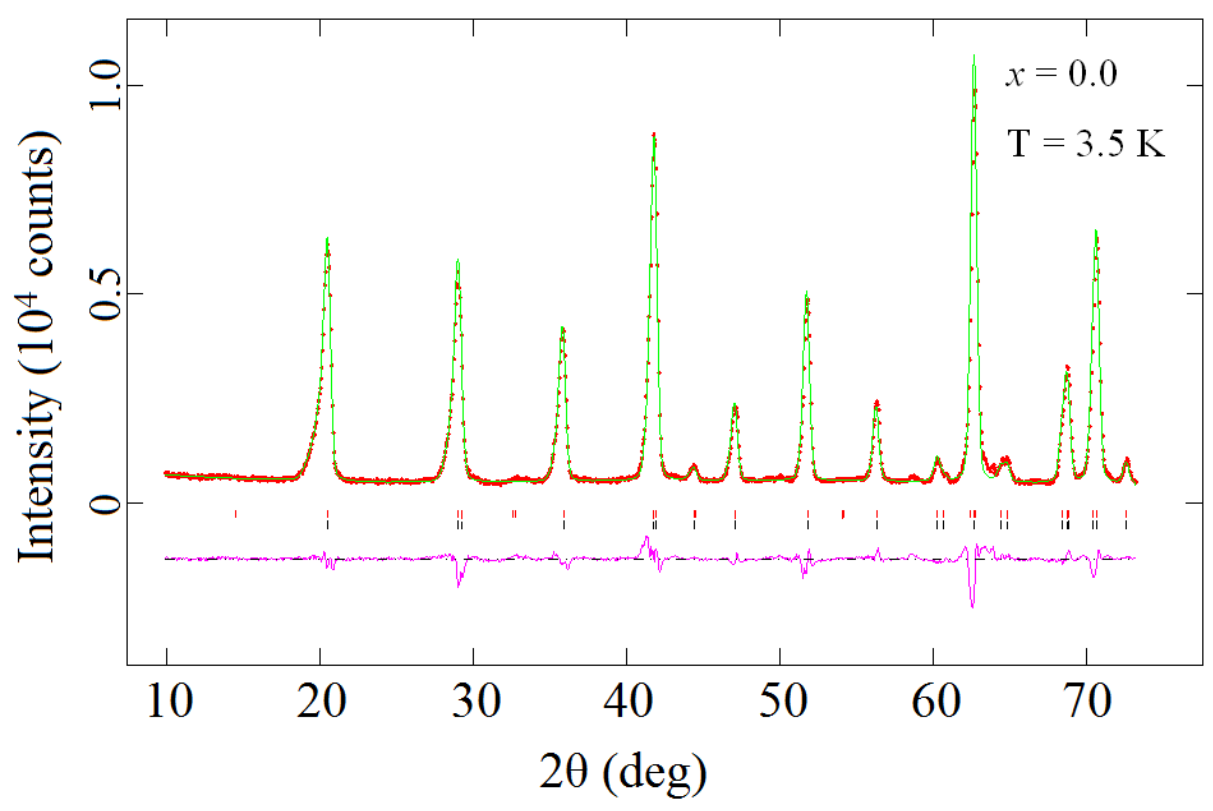

(b)

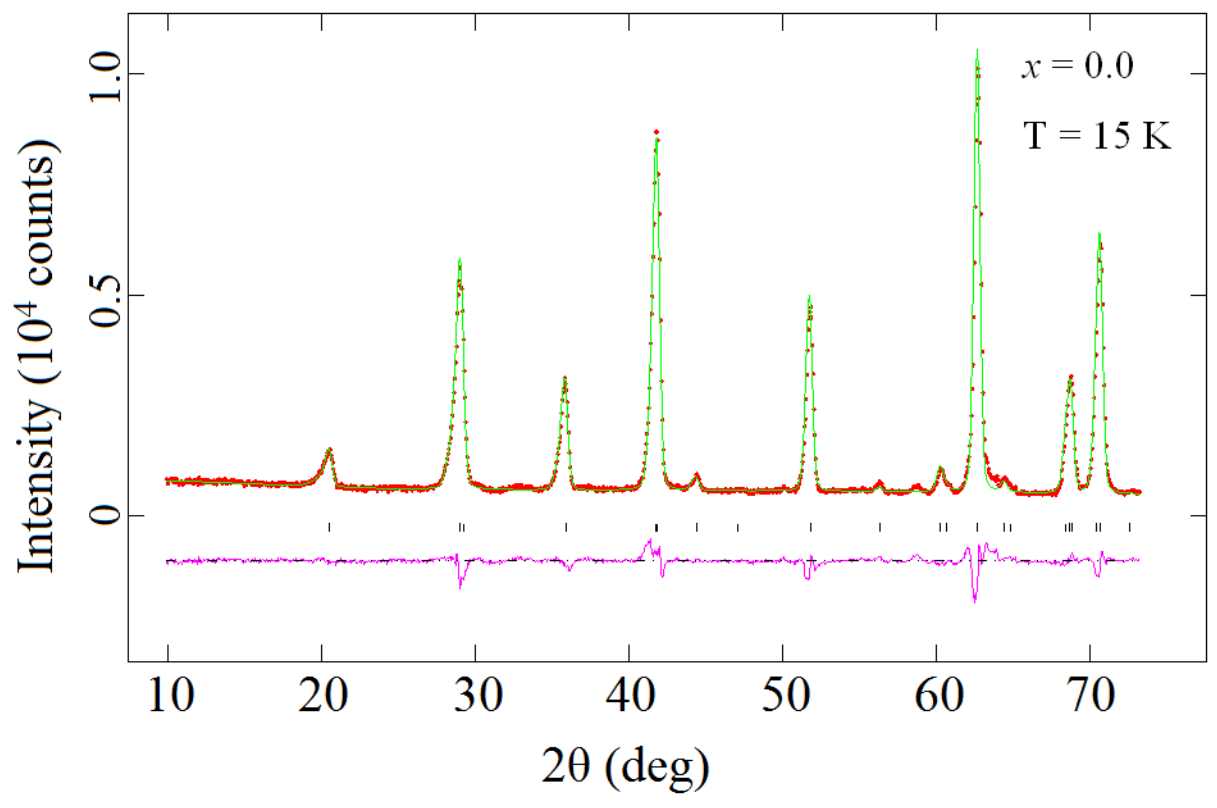

Figure 9 


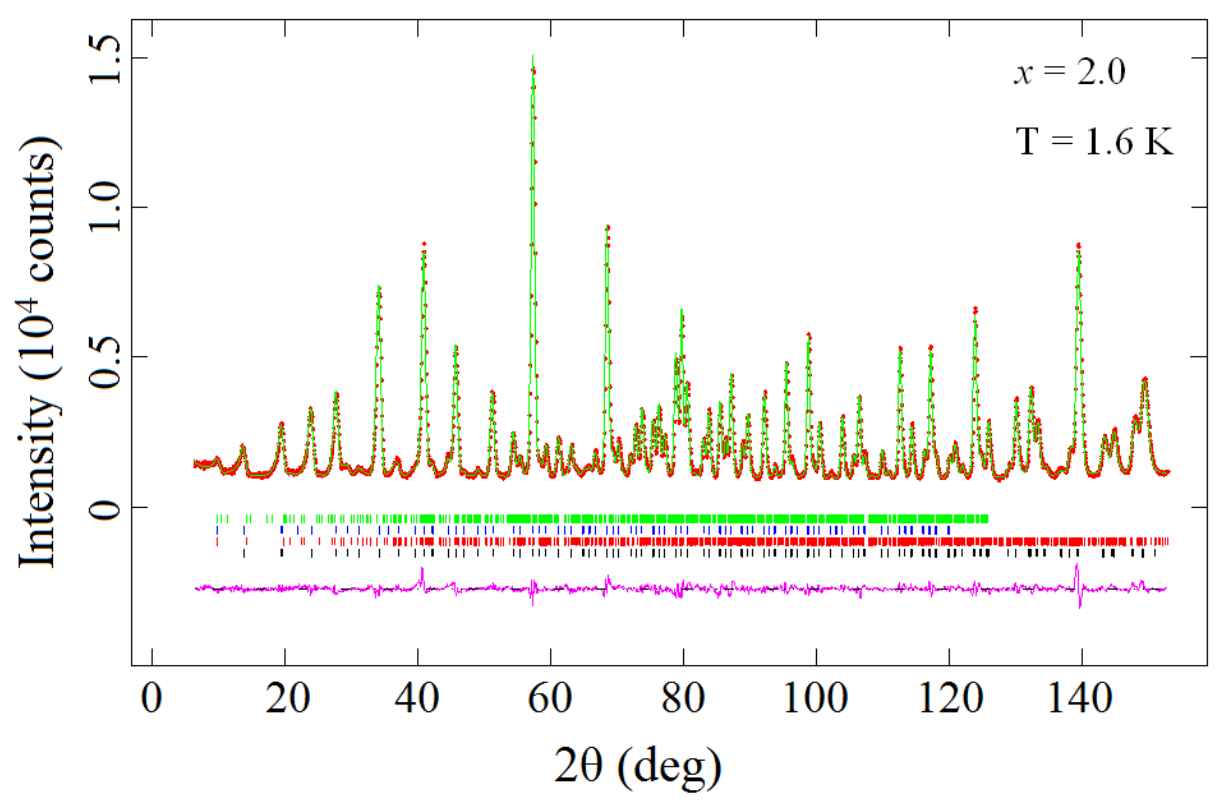

Figure 10

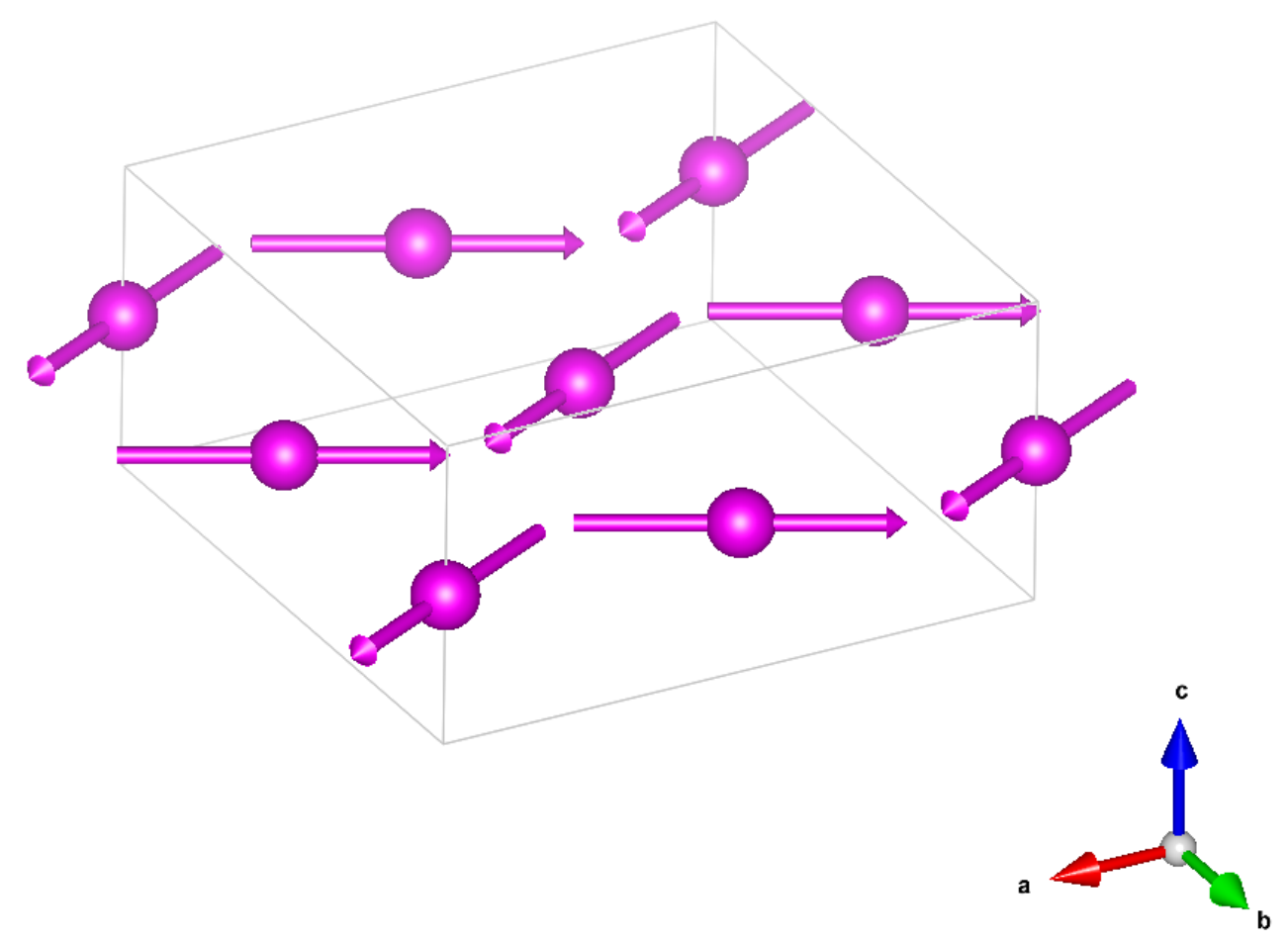

Figure 11 
(a)

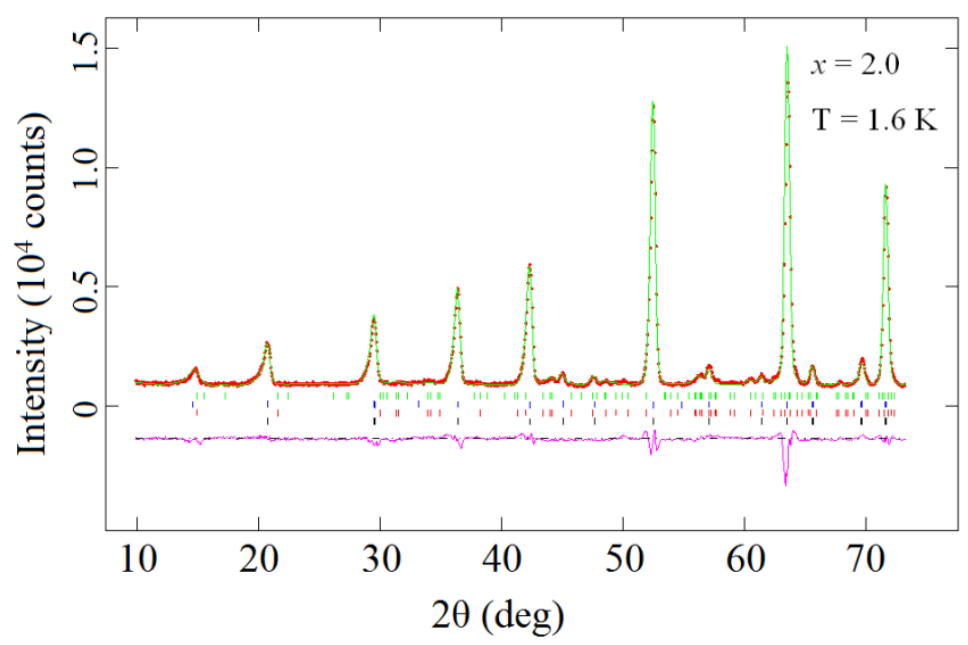

(b)

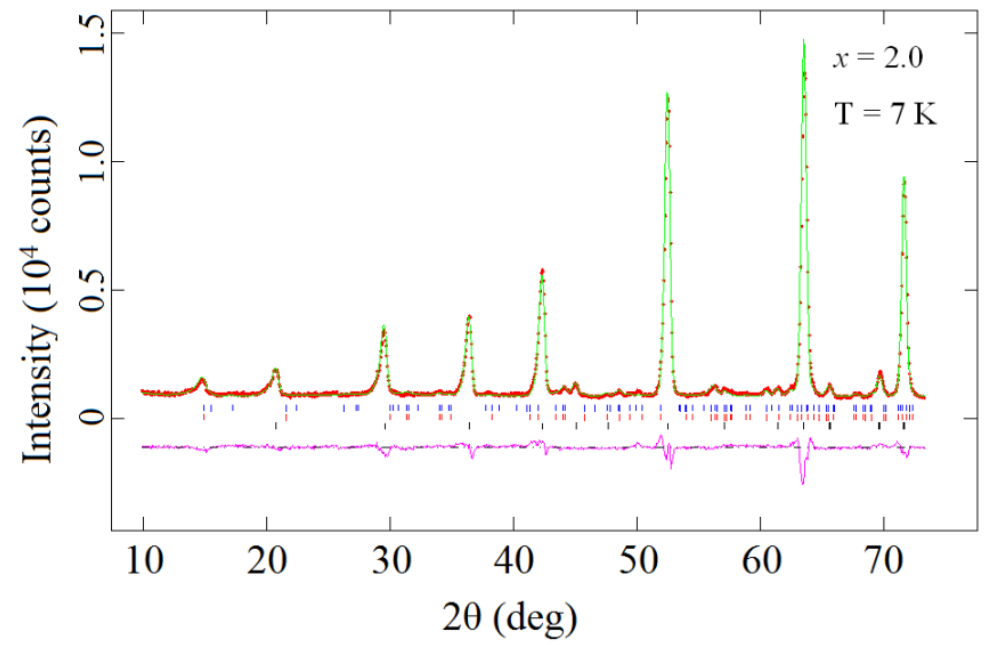

(c)

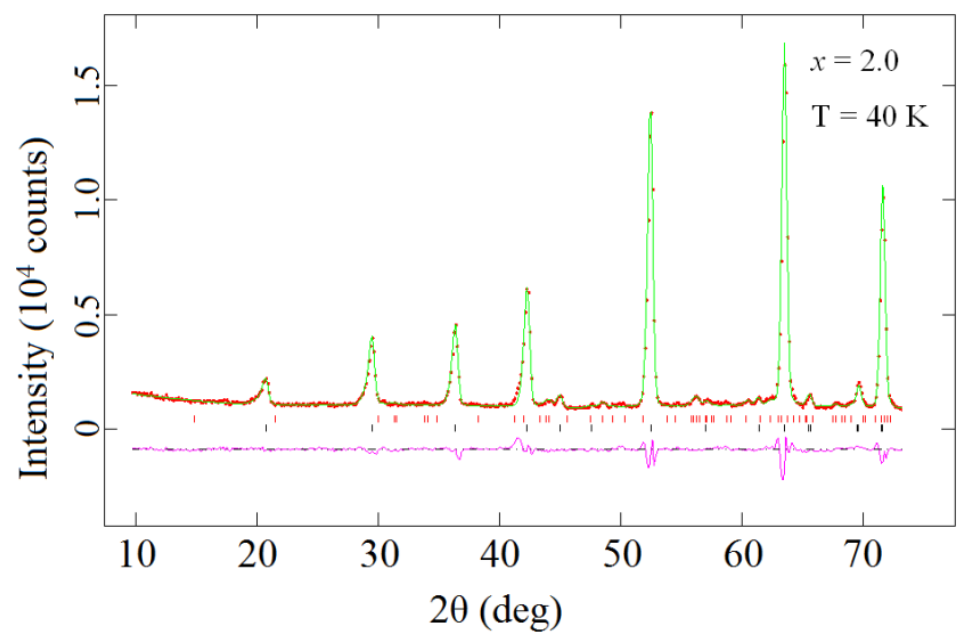

Figure 12 


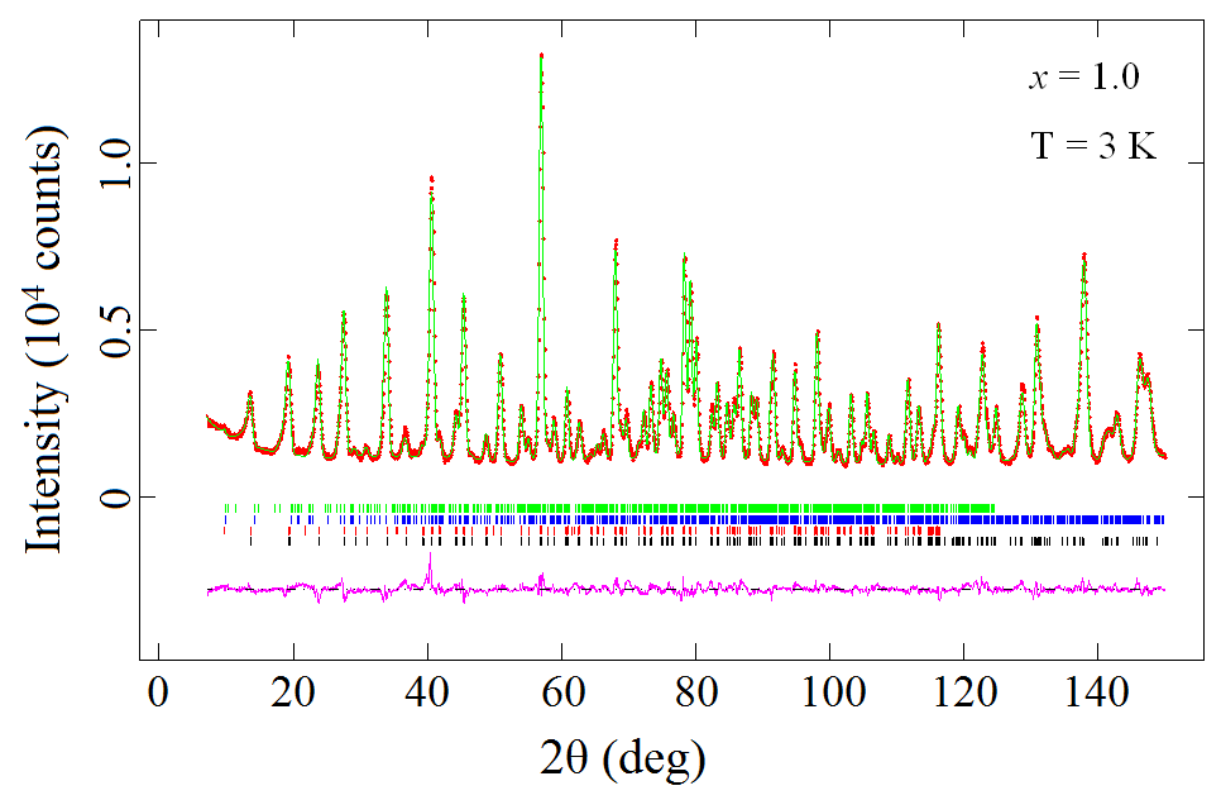

Figure 13 


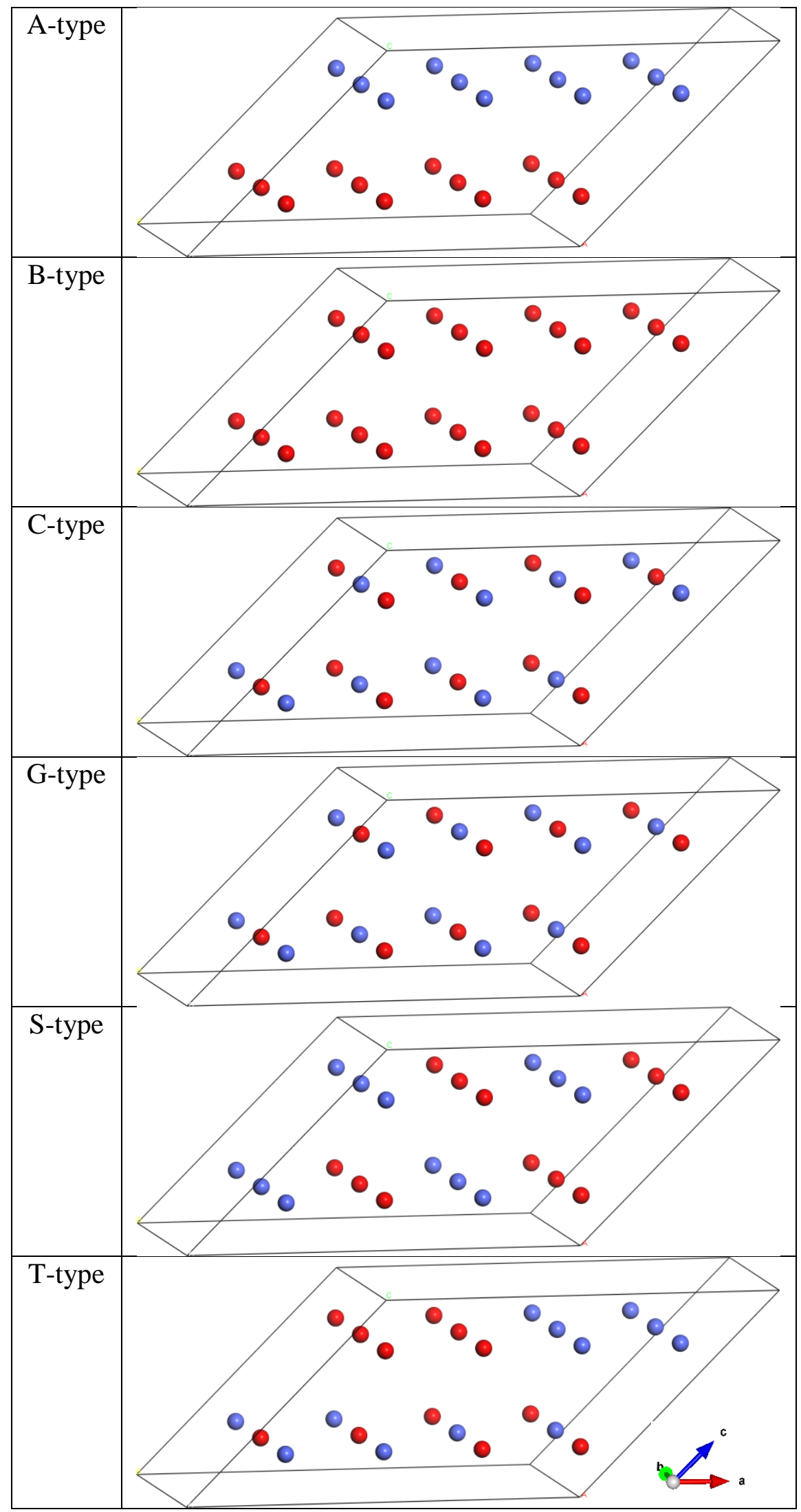

Figure 14 

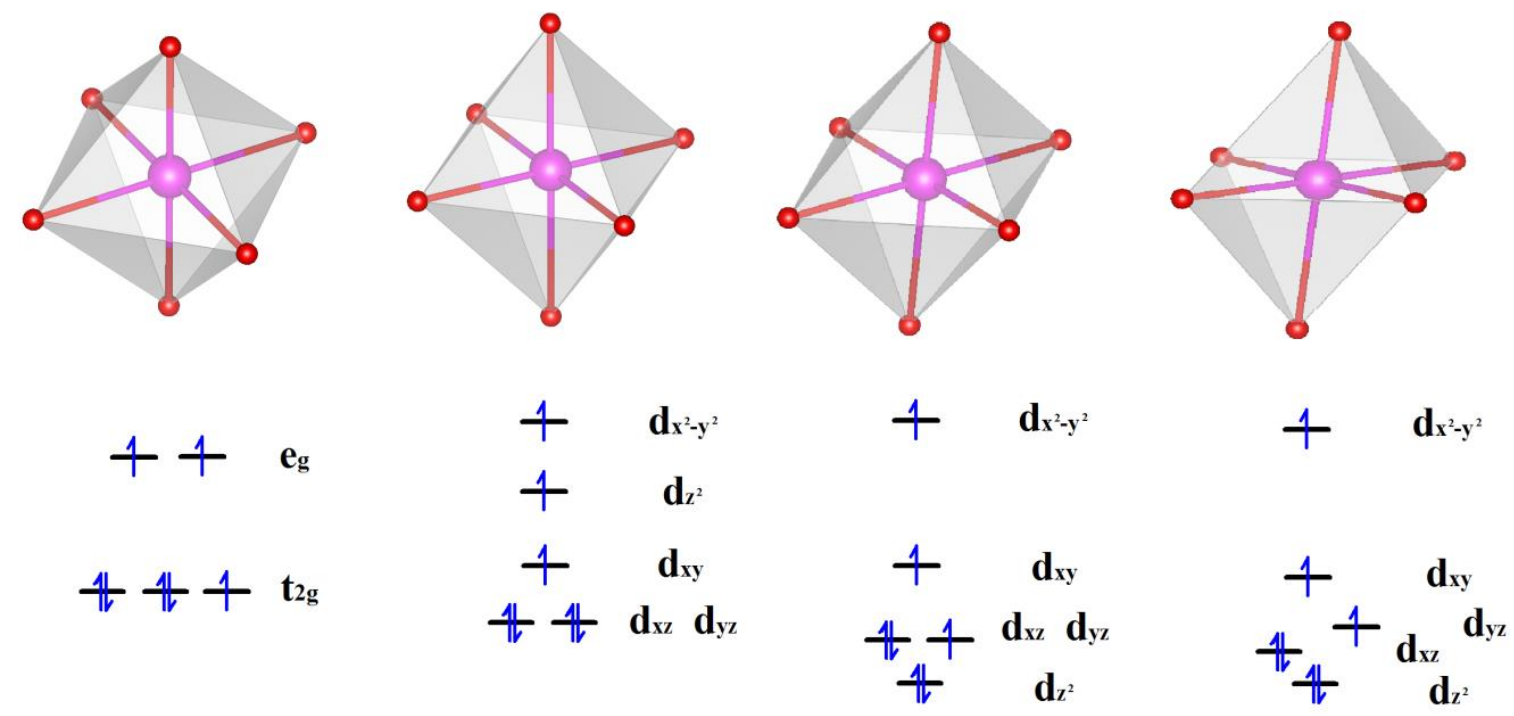

Figure 15 